\title{
A ANTA DOS CURRAIS DO GALHORDAS (CASTELO DE VIDE, ALTO ALENTEJO, PORTUGAL): ARQUITETURA, CRONOLOGIA E ANÁLISE QUÍMICA DE RESÍDUOS ORGÂNICOS DE RECIPIENTES CERÂMICOS
}

\author{
SÉRGIO MONTEIRO-RODRIGUES ${ }^{(1)} \&$ CÉSAR OLIVEIRA ${ }^{(2)}$
}

Resumo:

\begin{abstract}
Recorrendo à cromatografia gasosa com deteção por massa, analisaram-se os conteúdos orgânicos extraídos de três vasos da anta dos Currais do Galhordas, monumento erigido na segunda metade do $4^{\circ}$ milénio cal $\mathrm{BC}$ e reutilizado, pelo menos, no $3^{\circ}$ e no $2^{\circ}$ milénios cal BC.

Ao que tudo indica, os três vasos relacionam-se com a reutilização mais recente do monumento megalítico, durante o Bronze Pleno ( $2^{\circ}$ milénio cal BC). Em dois vasos identificaram-se vestígios de uva ou frutos vermelhos e peixe; no terceiro detetaram-se restos de gordura animal, possivelmente leite, associado a óleos de plantas. Os resultados obtidos a partir dos três recipientes cerâmicos estão em concordância com os observados por outros autores em amostras de época genericamente idêntica, recolhidas em áreas geográficas relativamente próximas da anta dos Currais do Galhordas.
\end{abstract}

Palavras-chave: Anta dos Currais do Galhordas; Conteúdos orgânicos em vasos; Megalitismo; Alto Alentejo.

Abstract:

\begin{abstract}
The megalithic tomb of Currais do Galhordas (Castelo de Vide, Alto Alentejo, Portugal): Architecture, chronology and chemical analysis of the organic content of ceramic vases

The organic content of three ceramic vases uncovered in the megalithic tomb of Currais do Galhordas (Central Eastern Portugal) - a monument built in the second half of the 4th millennium cal BC and reused in the 3th and in the 2nd millennia cal $\mathrm{BC}$ - was analysed by gas-chromatography with mass detection. The vases are allegedly connected with the latest use of the monument, during the Bronze Age (2nd millennium cal BC). Two of them presented traces of grapes or red fruits, together with fish; the third vase exhibited animal fat remains, possibly milk, associated with plant oils. Our results are compatible with other data from Iberian archaeological sites of identical period, in some cases located relatively close to the megalithic tomb of Currais do Galhordas.
\end{abstract}

Keywords: Anta dos Currais do Galhordas; Organic content in vases; Megalithism; Alto Alentejo.

Received: 20 September, 2017; Accepted: 20 November, 2017

Em memória do amigo Rui Boaventura que tão precocemente partiu..

\section{INTRODUÇÃO}

A região de Castelo de Vide é bastante rica em sepulturas megalíticas, encontrando-se inventariadas até ao momento mais de trinta. Estas sepulturas evidenciam alguma diversidade arquitetónica e normalmente fornecem material arqueológico em abundância e em bom estado de conservação. Por este facto encerram um enorme potencial no que diz respeito ao conhecimento do fenómeno tumular megalítico, não só do Alto Alentejo (e.g. ANDRADE 2009; BUENO RAMÍREZ et al. 2006, 2008, 2010, 2010a, 2012, 2013; OLIVEIRA 1995, 1997, 1997a, 2000; OliveIRA et al. 2007; PARREIRA 1996), como da Península Ibérica em geral.

Conhecidas desde há séculos (OLIVEIRA 1995, 1997), as antas de Castelo de Vide foram inicialmente estudadas por Pereira da Costa (CosTA 1868) e mencionadas por Júlio Basso (BASSO 1895) ainda na segunda metade do século XIX. Na primeira metade do século XX foram alvo da atenção de Tavares Proença Jr. (PROENÇA 1910), Possidónio M. Laranjo Coelho (COELHO 1924) e Georg e Vera Leisner (LEISNER \& LEISNER 1956, 1959, 1965). Numa época mais recente, Maria da Conceição Monteiro Rodrigues estudou estes monumentos para a elaboração da Carta Arqueológica do Concelho de Castelo de Vide (RoDRIGUEs 1975). Nos meados dos anos de 1990 foi apresentado o trabalho de maior fôlego sobre o megalitismo da região, da autoria de Jorge de Oliveira - Monumentos Megalíticos da Bacia Hidrográfica do Rio Sever (OLIVEIRA 1995).

${ }^{1}$ Universidade do Porto - Faculdade de Letras. Centro de Investigação Transdisciplinar Cultura Espaço e Memória (CITCEM). Via Panorâmica, s/n 4150-564 Porto, Portugal. Correio eletrónico: sergiomonteirorodrigues@gmail.com

${ }^{2}$ REQUIMTE/LAQV - Instituto Superior de Engenharia do Porto (ISEP). Rua Dr. António Bernardino de Almeida, 431, 4249-015 Porto, Portugal / Universidade do Porto - Faculdade de Letras. Departamento de Ciências e Técnicas do Património. Via Panorâmica, s/n 4150-564 Porto, Portugal. Correio eletrónico: cesar.oliveira@graq.isep.ipp.pt 
Num contexto mais amadorístico, o Grupo de Arqueologia de Castelo de Vide, criado nos inícios dos anos de 1980, procedeu à escavação de algumas antas do concelho, constituindo uma importante coleção de artefactos, atualmente depositados na Secção de Arqueologia da autarquia. Os recipientes cerâmicos que integram a referida coleção foram recentemente estudados por Ana Paroleiro (PAROLEIRO 2016) no âmbito de um trabalho académico.

Apesar de mais de um século de investigações, existem ainda inúmeras lacunas no que toca ao conhecimento do megalitismo da região de Castelo de Vide (e do megalitismo Alto-alentejano em geral), nomeadamente no que diz respeito ao seu enquadramento cronológico, à caracterização arquitetónica dos monumentos e à identificação dos "pacotes artefatuais" relativos às diferentes etapas da sua utilização (e.g. MATALOTO 2007; ANDRADE 2016).

Em relação à anta dos Currais do Galhordas, a sua escavação decorreu no quadro de um projeto de valorização turística, cultural e ambiental da envolvente da albufeira da barragem de Póvoa e Meadas, promovido pelo Município de Castelo de Vide, que contempla, entre outros aspetos, o res- tauro, a divulgação, a musealização e o estudo científico de alguns elementos patrimoniais daquela área (MONTEIRO-Rodrigues, 2013, 2016; OLIVEIRA et al. 2015). Foi neste contexto que se realizaram as datações pelo radiocarbono e as análises de resíduos orgânicos a que agora se faz referência, visando assim contribuir para um melhor conhecimento do fenómeno tumular megalítico do centrosul de Portugal. De facto, para além das lacunas ao nível da cronologia, também nunca tinham sido realizados estudos no sentido de identificar os conteúdos dos recipientes cerâmicos usados nas inumações (OLIVEIRA et al. 2015).

\section{A ANTA DOS CURRAIS DO GALHORDAS}

\subsection{Breve descrição do monumento e do respe- tivo espólio}

Descoberta em 1993 por membros da Secção de Arqueologia da Câmara Municipal de Castelo de Vide, a anta dos Currais do Galhordas - localizada na Tapada do Souto, freguesia de S. João Baptista, concelho de Castelo de Vide, distrito de Portalegre (Fig. 1) - foi escavada por um dos autores (S. Monteiro-Rodrigues) em 2011, 2013 e 2015.

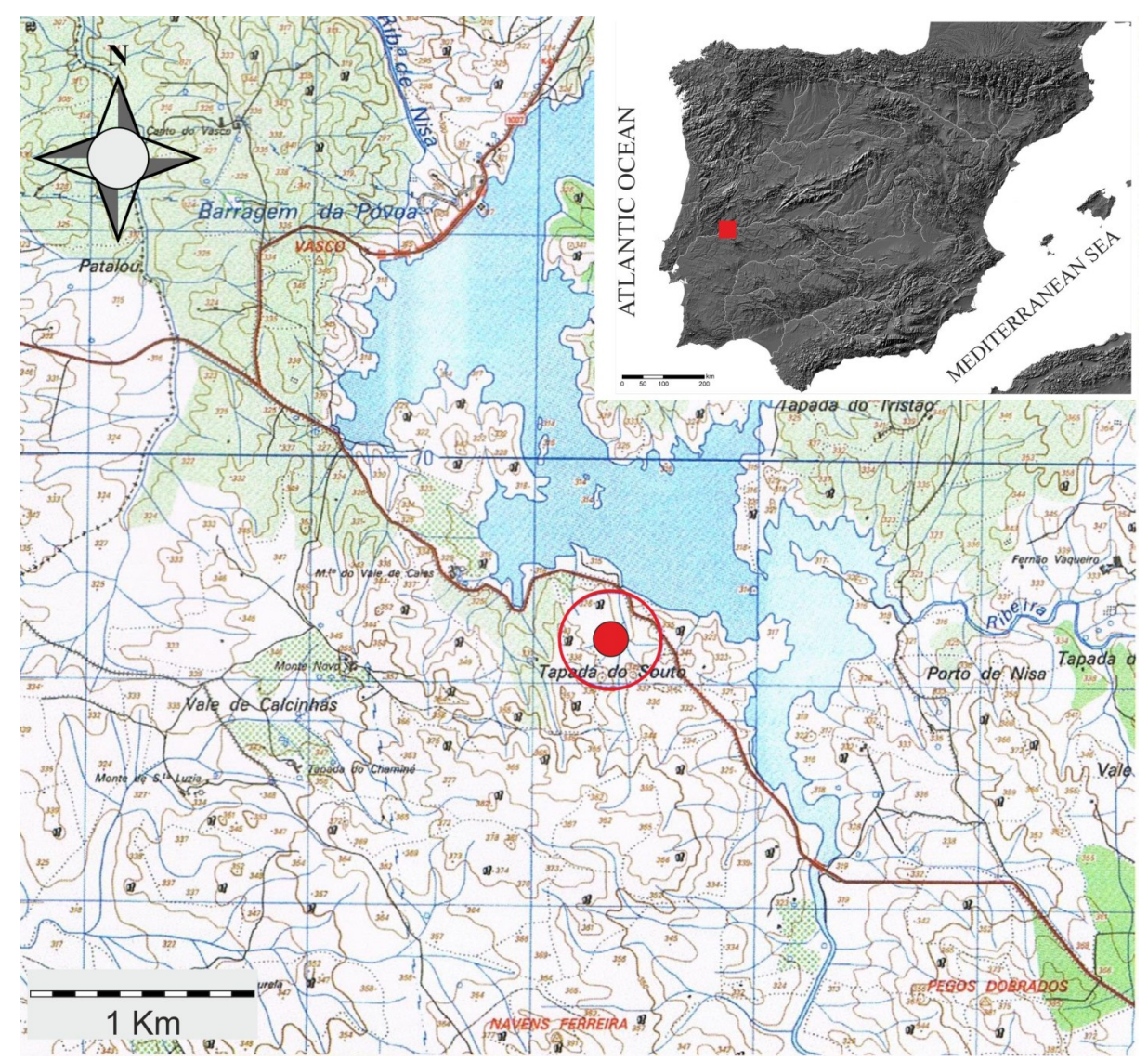

Fig. 1. Localização da anta dos Currais do Galhordas em extrato da Carta Militar de Portugal, na escala 1:25000, folha 335 (Castelo de Vide), 1999. Coordenadas geográficas: 39 27' 40,4' $\mathrm{N} 07^{\circ} 32^{\prime}$ ' 39,9' ' W Greenwich.

Fig. 1. Location of the megalithic tomb of Currais do Galhordas. Cartography: Carta Militar de Portugal, scale 1:25000, sheet 335 (Castelo de Vide), 1999. Geographic coordinates: 39² 27' 40.4”' N $07^{\circ} 32$ ' 39.9' W Greenwich. 
Do ponto de vista arquitetónico, a anta dos Currais do Galhordas é um monumento megalítico construído em granito, com câmara poligonal definida por sete esteios e corredor longo ligeiramente desviado relativamente ao eixo de simetria da anta (Monteiro-Rodrigues 2013, 2016). Tal como acontece na maior parte dos dólmenes da região, o corredor cumpre a normal orientação a leste (OLIVEIRA 1995, 1997) (Fig. 2).

A mamoa é composta essencialmente por blocos de granito embalados num sedimento arenoso, por vezes areno-siltoso, adquirindo por isso uma grande compacidade. Os referidos blocos tendem a adensar-se junto à câmara funerária, funcionando assim como contraforte dos respetivos esteios. Sob esta camada de "terra" e pedras surge um depósito arenoso grosseiro que parece corresponder ao "solo" antigo no qual foram fincados os esteios do monumento (MONTEIRO-RODRIGUES 2013, 2016) (Fig. 3).

Tendo como referência outros monumentos megalíticos do concelho de Castelo de Vide (Oliveira 1995, 1997), pode dizer-se que a anta dos Currais do Galhordas é extremamente pobre no que toca à pedra talhada, nomeadamente às pontas de seta e aos micrólitos geométricos. Os vasos cerâmicos, por sua vez, aparecem em número significativo e demonstram alguma variedade morfotipológica (MONTEIRO-RODRIGUES 2013, 2016), possivelmente reflexo das inúmeras utilizações que a anta foi tendo ao longo dos tempos (OLIVEIRA 1995, 1997; MONTEIRO-RODRIGUES 2013, 2016) (Fig. 4).

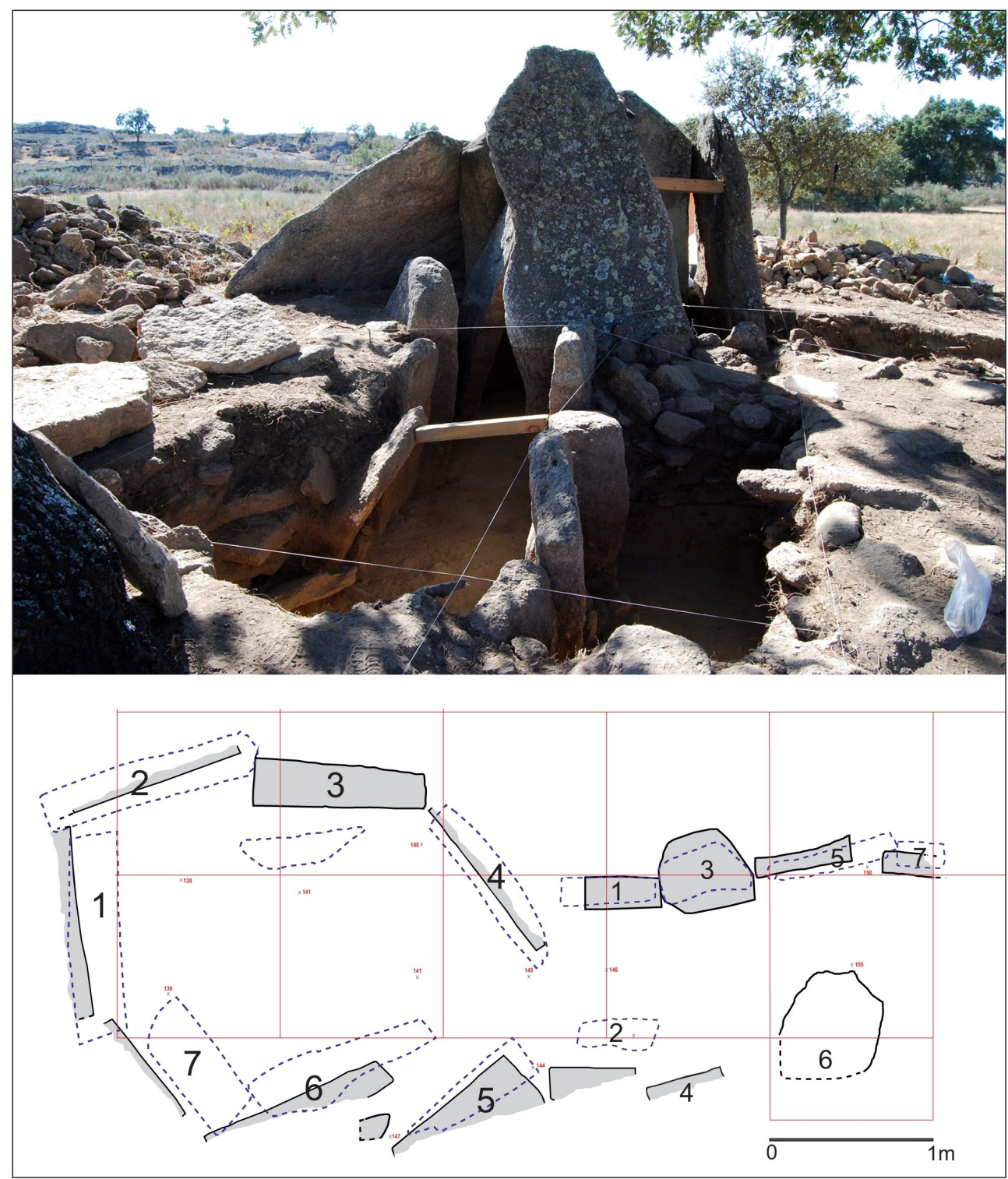

Fig. 2. Em cima: anta dos Currais do Galhordas vista de este. Em baixo: planta da anta.

Fig. 2. Top: Megalithic tomb of Currais do Galhordas (view from east). Bottom: Plan of the tomb. 


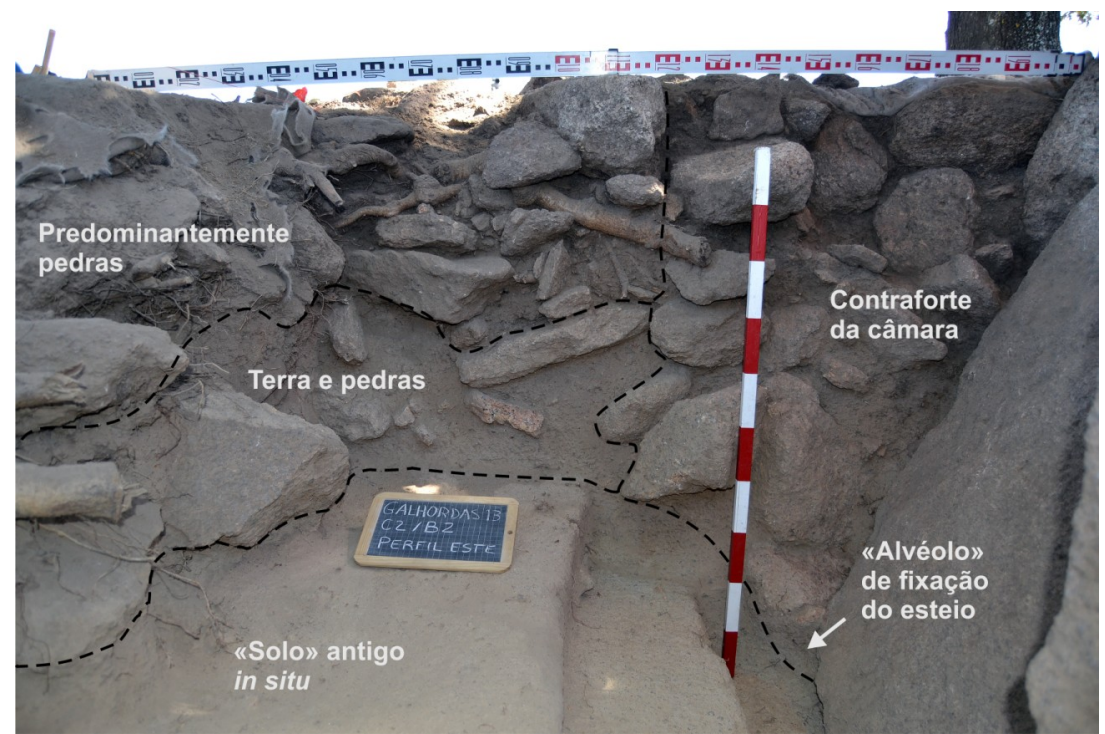

Fig. 3. Estrutura interna da mamoa e contraforte dos esteios da câmara funerária.

Fig. 3. The fabric of the mound and the buttress of the megalithic chamber (a mixture of silty sand and stone).

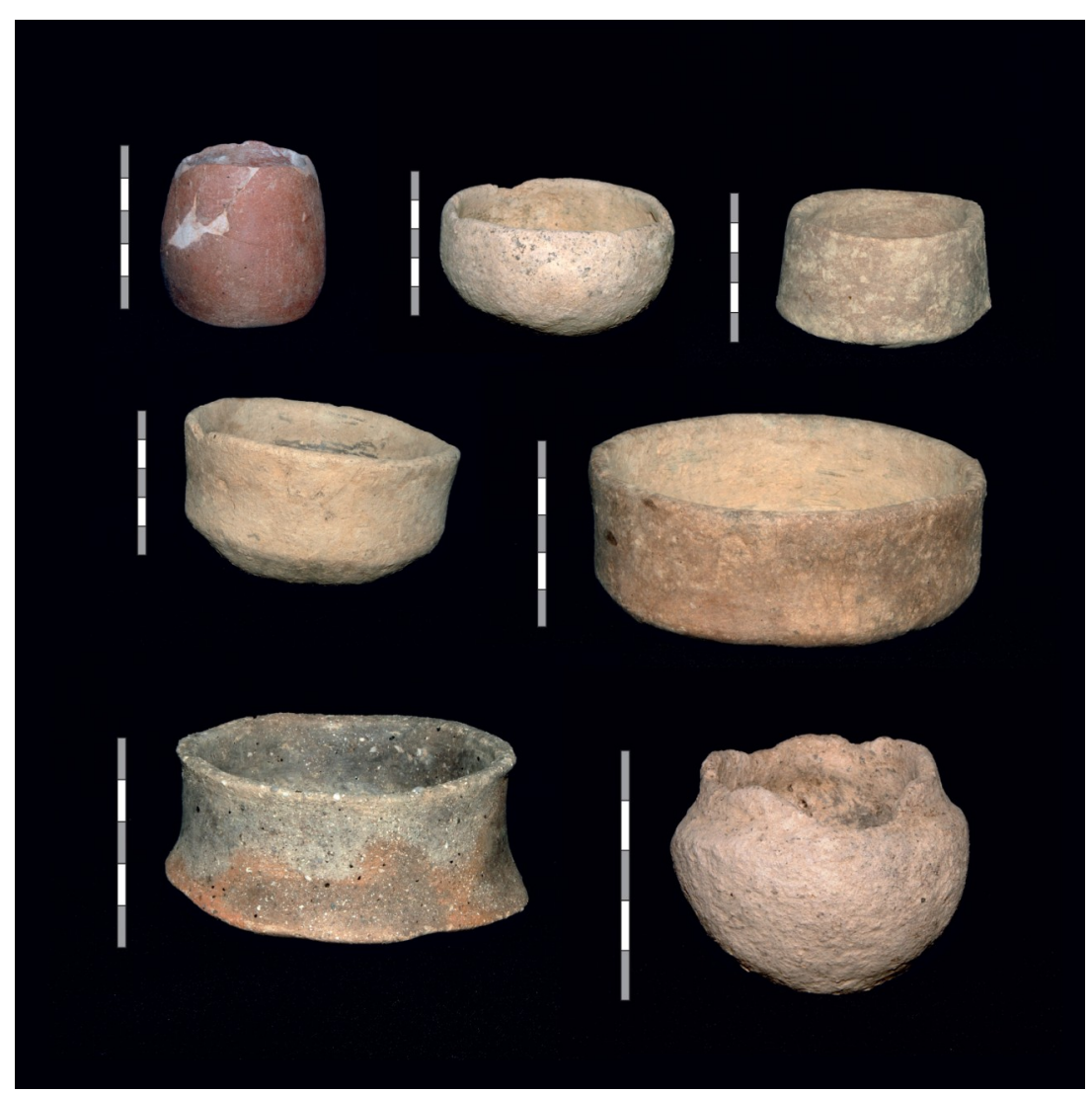

Fig. 4. Alguns dos vasos cerâmicos exumados na anta dos Currais do Galhordas.

Fig. 4. Some pottery found in the megalithic tomb of Currais do Galhordas.

Estas utilizações, para além de gerarem a diversidade do espólio, terão tido simultaneamente repercussões na própria estrutura do monumento megalítico, criando-se em determinadas alturas eventuais novos acessos à câmara funerária e ao corredor, quer através da fraturação de esteios (tal como também sucede, por exemplo, na anta da Bola de Cera, Marvão), quer através da sua substituição por blocos de granito de menores dimensões, mais facilmente amovíveis, ou mesmo por construções em pedra seca (MONTEIRORoDRIGUES 2013, 2016; OLIVEIRA 1995, 1997). 
Durante a campanha de escavação de 2015 verificou-se que o corredor da anta dos Currais do Galhordas, numa determinada fase, foi alvo de um prolongamento realizado com pequenas pedras, terminando numa espécie de átrio no lado da entrada (Fig. 5). Originalmente seria, portanto, um corredor médio e não um corredor longo (GONÇALVES 1989), como passou a ser após tal intervenção.

Neste prolongamento, a ocorrência de placas de "xisto" - uma lisa, aparentemente reconfigurada, e pelo menos um fragmento gravado - e de fragmentos de recipientes cerâmicos com decorações e morfologias que segundo alguns autores podem ser consideradas "tardias" (BOAVENTURA \& MATALOTO 2013; CARDOSO \& GRADIM 2008; MATALOTO 2007, 2018-no prelo) (Fig. 6a) sugere que estas ações (re)construtivas terão decorrido em etapas posteriores à construção do monumento. Efetivamente, uma das datações da anta das Castelhanas (Marvão), obtida a partir de ossos humanos queimados - 3220 \pm 65 BP (OxA-5432)/ 1657-1309 cal BC $2 \sigma-$, mostra que nos meados do $2^{\circ}$ milénio cal $\mathrm{BC}$ os monumentos megalíticos da região eram ainda utilizados para fins funerários (e/ou outros?), estando muito provavelmente sujeitos a vários tipos de modificações (OliveIRA 1997a). No caso da anta dos Currais do Galhordas, a única datação obtida para o corredor, como adiante se verá, remete igualmente para a Idade do Bronze, conectandose com ela não só os fragmentos cerâmicos da figura 6a, como também uma deposição primária de vasos, identificada na campanha de 2011, que integra pelo menos um com carena baixa (MONTEIRORODRIGUES 2013) (Fig. 6b).

Perante tais evidencias percebe-se que as antas são, sem dúvida, arquiteturas extremamente dinâmicas, estando assim sujeitas a remodelações tão frequentes que se torna praticamente impossível estabelecer com detalhe as diferentes etapas da sua "biografia".

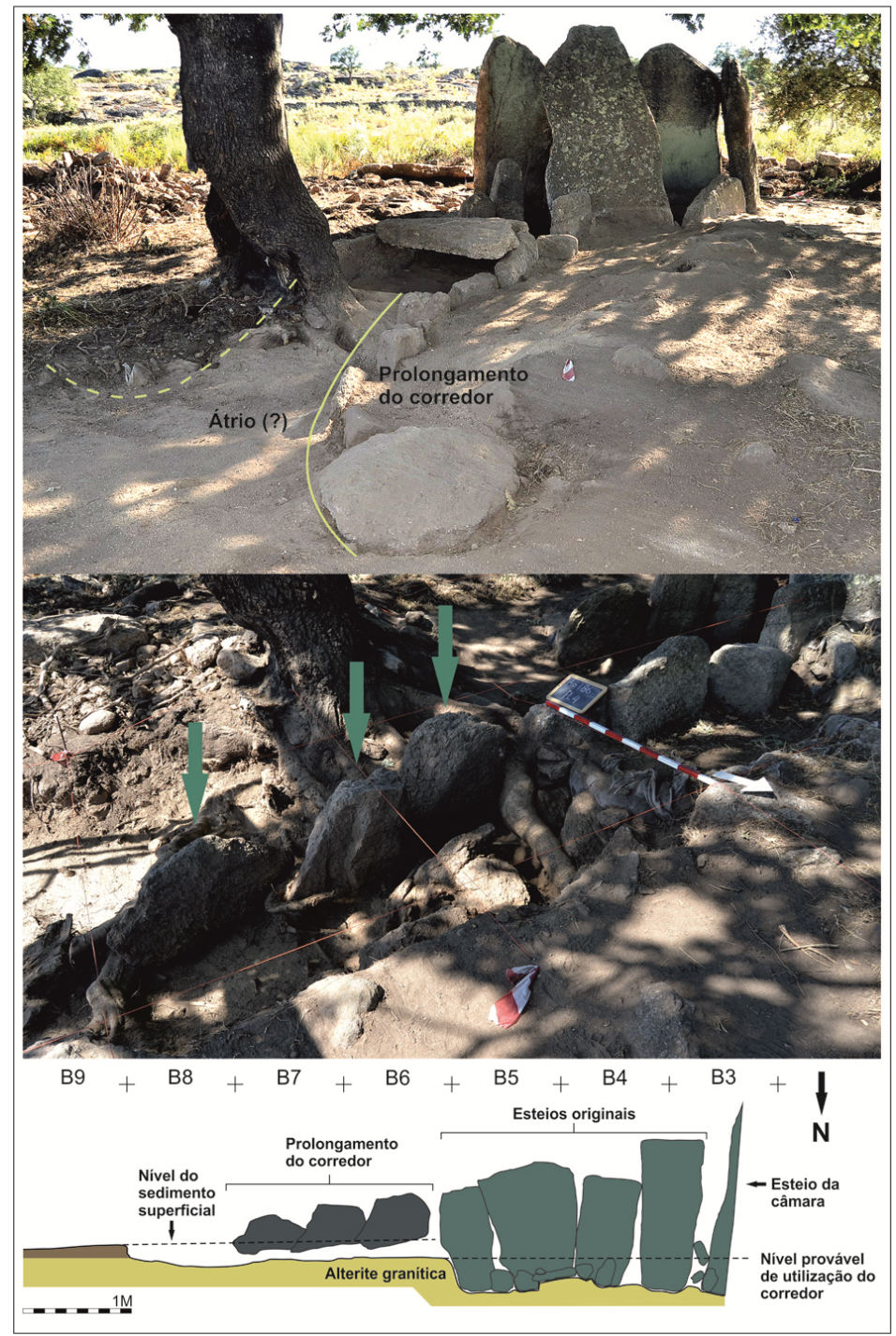

Fig. 5. Prolongamento do corredor e possível átrio.

Fig. 5. Extension of the tomb passage, with a possible atrium. 

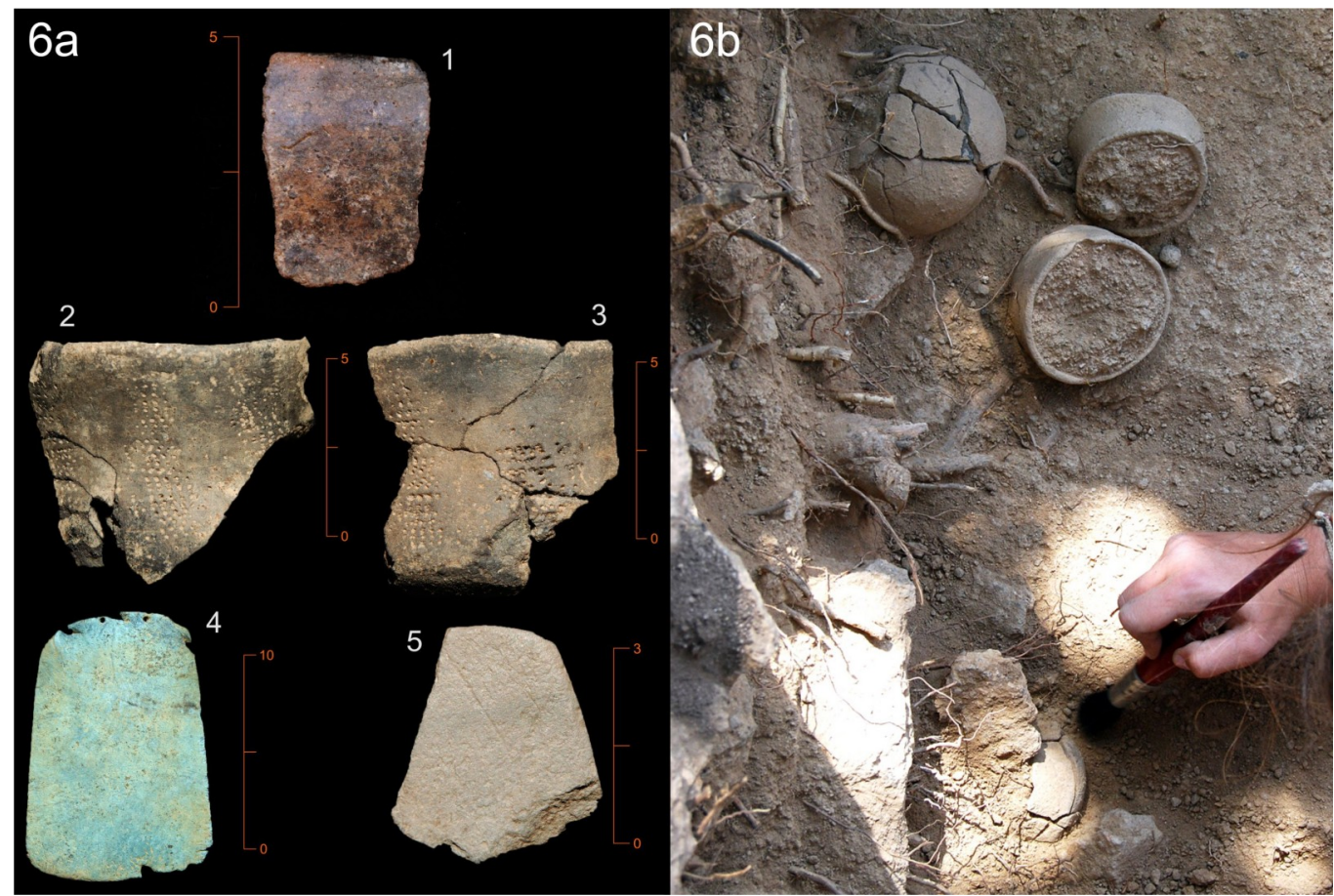

Fig. 6. 6a: 1. Fragmento cerâmico (bordo) com superfícies interna e externa brunidas; 2. Vaso de morfologia campanular com decoração por puncionamento; 3. Taça com paredes côncavas e carena baixa, com decoração por puncionamento; 4 . Placa de "xisto" lisa, aparentemente reafeiçoada; 5. Fragmento de placa de "xisto" com incisão em triângulo. 6b: Conjunto de vasos cerâmicos depositados no corredor (deposição primária).

Fig. 6. 6a: 1. Shard (rim) with burnished internal and external surfaces; 2 . Bell-shaped vase with punctured decoration; 3 . Concave body bowl with low carination and punctured decoration; 4 . Unengraved slate plaque apparently reshaped; 5 . Fragment of slate plaque with a triangular incision. $\mathbf{6 b}$. Set of vases uncovered in the passage corresponding to a "primary deposition".

\subsection{Cronologia}

A inexistência de materiais orgânicos normalmente designados de "vida curta" (e.g. REIMER 2009) na anta dos Currais do Galhordas determinou que as datações pelo radiocarbono fossem realizadas a partir de fragmentos de carvão de Quercus, o único material orgânico exumado durante os trabalhos de escavação. A sua análise antracológica identificou dois fragmentos de car- vão de reduzido calibre, correspondendo a pequenos ramos, e um outro de calibre indeterminado.

Em princípio, os resultados radiométricos relativos aos pequenos ramos não estarão afetados pelo efeito de "madeira antiga" (Idem). Em relação ao fragmento de calibre indeterminado, é possível afirmar apenas que o resultado da sua datação é inteiramente compatível com a realidade arqueológica observada.

Quadro 1. Anta dos Currais do Galhordas: datações pelo radiocarbono.

Table 1. Currais do Galhordas megalithic tomb: radiocarbon dates.

\begin{tabular}{|c|c|c|c|c|c|}
\hline $\begin{array}{l}\text { Amostra } \\
\text { Ref. Lab. }\end{array}$ & Contexto & Material datado & $\mathrm{C} 13 / \mathrm{C} 12$ & Idade ${ }^{14} \mathrm{C}$ & Cal BC $2 \sigma$ \\
\hline $\begin{array}{c}\mathrm{S} 4 \\
16 \mathrm{C} / 0308\end{array}$ & $\begin{array}{c}\text { Quadrícula Z'-1 } \\
\text { Z: } 180 \mathrm{~cm} \\
\text { Base do esteio de cabe- } \\
\text { ceira }\end{array}$ & $\begin{array}{l}\text { Quercus perenifólia } \\
\text { (pequeno ramo) }\end{array}$ & $-23.7 \mathrm{o} / \mathrm{oo}$ & $4480 \pm 30$ BP & $\begin{array}{l}3340-3203(0,58) \\
3199-3088(0,38) \\
3058-3030(0,05)\end{array}$ \\
\hline $\begin{array}{c}\mathrm{S} 1 \\
15 \mathrm{C} / 0440\end{array}$ & $\begin{array}{c}\text { Quadrícula A2 } \\
\text { Z: } 140 \mathrm{~cm} \\
\text { Base da câmara } \\
\text { Assoc. microl. geom. }\end{array}$ & Quercus sp. & $-23.1 \mathrm{o} / \mathrm{oo}$ & $3950 \pm 40 \mathrm{BP}$ & $\begin{array}{l}2571-2512(0,23) \\
2504-2336(0,76) \\
2323-2307(0,02)\end{array}$ \\
\hline $\begin{array}{c}\mathrm{S} 2 \\
15 \mathrm{C} / 0441\end{array}$ & $\begin{array}{c}\text { Quadrícula A3 } \\
\text { Z: } 131 \mathrm{~cm} \\
\text { Sob laje soleira entre } \\
\text { corredor e câmara }\end{array}$ & $\begin{array}{l}\text { Quercus caducifólia } \\
\text { (pequeno ramo) }\end{array}$ & $-25.1 \mathrm{o} / \mathrm{oo}$ & $3300 \pm 40 \mathrm{BP}$ & $1683-1499(100)$ \\
\hline $\begin{array}{c}\mathrm{S} 3 \\
15 \mathrm{OS} / 0442\end{array}$ & $\begin{array}{c}\text { Quadrícula B1 } \\
\text { Z: } 129 \mathrm{~cm} \\
\text { Câmara funerária }\end{array}$ & $\begin{array}{c}\text { Sedimento orgânico } \\
\text { extraído do vaso } 10 \\
\text { (taça com carena baixa) }\end{array}$ & $-24.5 \mathrm{o} / \mathrm{oo}$ & $2270 \pm 40 \mathrm{BP}$ & $\begin{array}{l}402-347(0,43) \\
319-207(0,57)\end{array}$ \\
\hline
\end{tabular}


Fragmentos de carvão recolhidos na base do esteio de cabeceira da anta (amostra S4) (Fig. 7), muito possivelmente resultantes de ações relacionadas com o momento da sua construção, permitiram datá-la dos últimos 300 anos do $4^{\circ}$ milénio cal $\mathrm{BC}(4480 \pm 30 \mathrm{BP} / 3340-3030$ cal BC $2 \sigma)$ (Quadro 1). Este intervalo coincide com o obtido a partir da calibração da datação proveniente da anta dos Coureleiros 4 (Coureleiros $2 \mathrm{seg}$. LEISNER \& LEISNER 1959), a cerca de $6,5 \mathrm{~km}$ a SE da anta dos Currais do Galhordas - 4240 \pm 150 BP (ICEN 976) / 33382471 cal BC $2 \sigma$ (Oliveira 1995, 1997). Assim, e ao que tudo indica, os monumentos com câmara poligonal, corredor médio e corredor longo (como Coureleiros 4) terão sido erigidos na região pelo menos a partir dos últimos séculos do $4^{\circ}$ milénio cal BC, ou seja, num período que coincide com o apogeu da construção de sepulcros megalíticos (Oliveira 1995, 1997; BOAVENTURA 2009; BUENO RAMÍREZ et al. 2010; ANDRADE 2016).

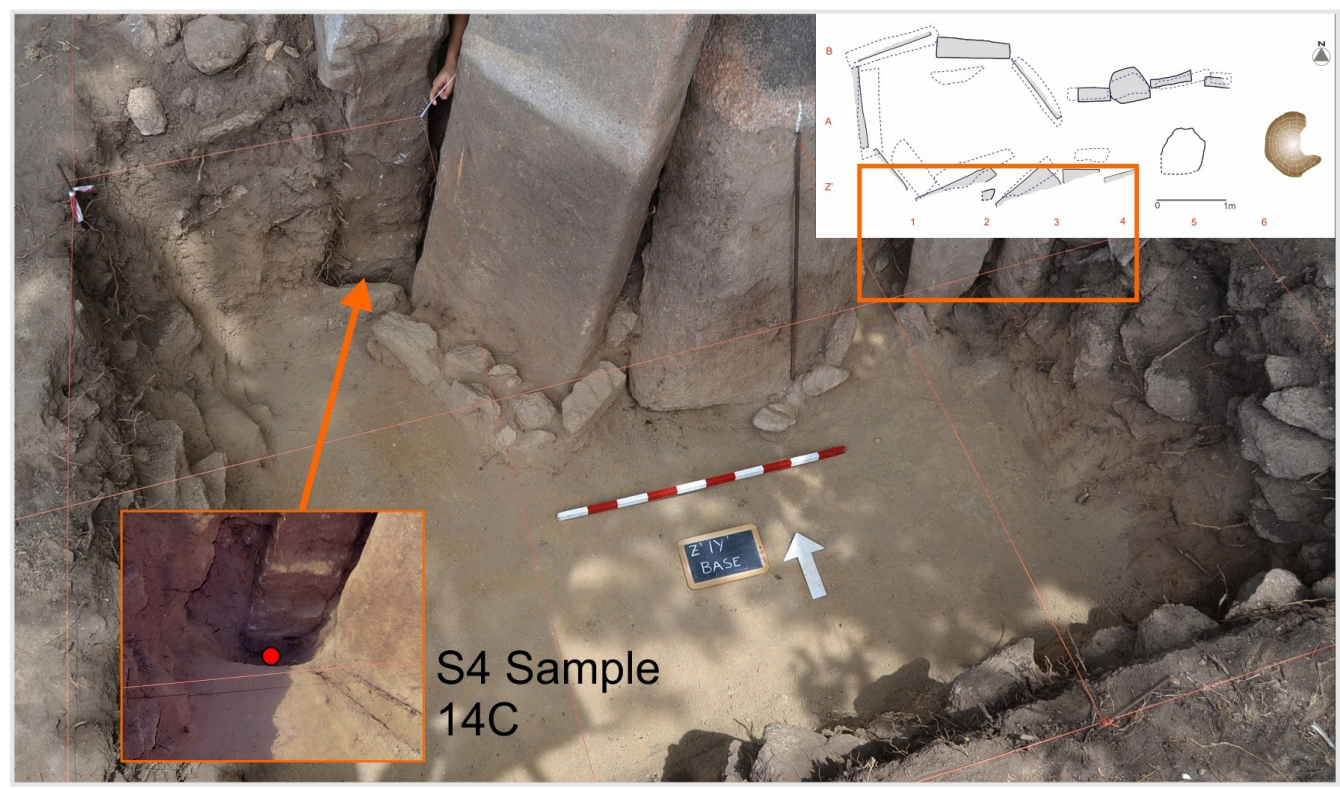

Fig. 7. Localização da amostra de carvão S4 datada pelo Carbono 14.

Fig. 7. Location of the S4 sample which was radiocarbon dated.

A descoberta, durante a campanha de escavação de 2013, de uma ponta de seta de base convexa em quartzito xistento - tipologia que aponta genericamente para o Neolítico final (LEISNER \& LEISNER 1951, 1965; LEISNER 1983; FORENBAHER 1999; BOAVENTURA 2009; ANDRADE 2016) - por baixo do contraforte da câmara funerária, no contacto com o depósito arenoso que sustem os respetivos esteios, é compatível com este resultado cronométrico.

As duas outras datações com valores enquadráveis na pré-história - 3950 $\pm 40 \mathrm{BP} / 2571-2307$ cal BC $2 \sigma$ e $3300 \pm 40 \mathrm{BP} / 1683-1499$ cal BC $2 \sigma-$ indicam a reutilização da anta dos Currais do Galhordas, respetivamente, no terceiro quartel do $3^{\circ}$ milénio cal BC (datação obtida a partir de uma amostra recolhida na câmara funerária - amostra S1) e no segundo quartel do $2^{\circ}$ milénio cal BC (datação obtida a partir de uma amostra recolhida sob uma laje soleira que demarca o final do corredor e o início da câmara funerária - amostra S2) (Fig. 8). Seguindo a proposta de BoAvEnTURA \& MATALOTO (2013), a primeira datação poderia articular-se com um período já posterior ao uso das placas de "xisto" gravadas - "fase 4 - pós ídolosplaca" (BOAVENTURA \& MATALOTO 2013: 95)

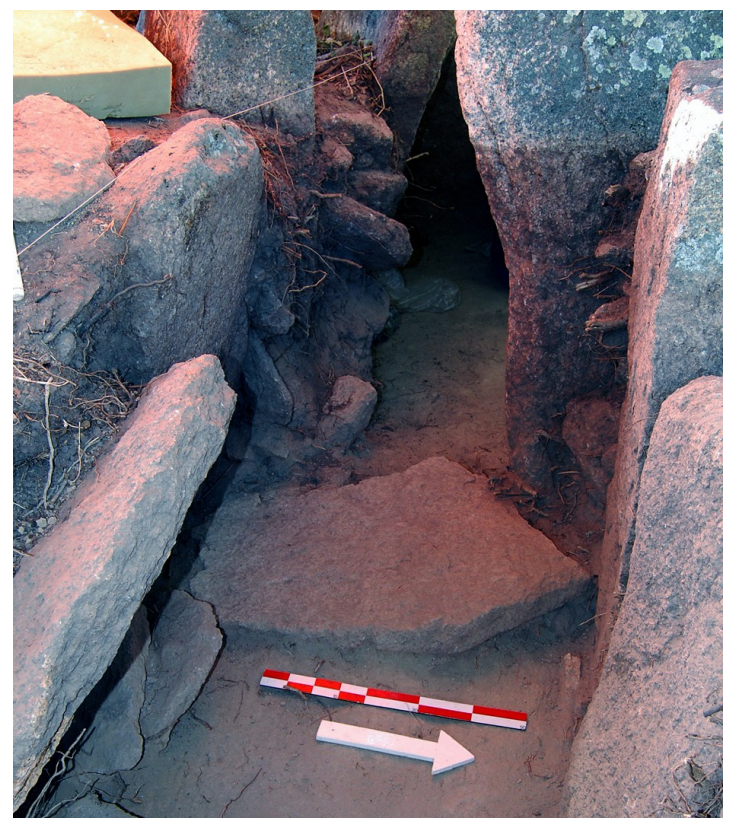

Fig. 8. Laje soleira sob a qual foi recolhida a amostra de carvão S2 submetida a datação pelo carbono 14 .

Fig. 8. Granite slab (delimiting the area between the chamber and the passage) under which sample S2 was collected for radiocarbon dating. 
(Fig. 9) - as quais, na anta dos Currais do Galhordas, surgem nas terras da mamoa (fragmentos), no prolongamento do corredor e na câmara funerária, havendo pelo menos duas com claras evidências de reafeiçoamento (MONTEIRO-RODRIGUES 2013, 2016) (Fig. 10).

A segunda datação marca uma etapa de utilização tardia do sepulcro (final da "fase 4"), já durante o Bronze Pleno (OliveIRA 1995, 1997, 1997a, 1998, 1999-2000; BOAVENTURA \& MATALOTO 2013; MATALOTO 2007, 2018-no prelo). Ou seja, remete para um momento em que se "poderá não ter gerado a construção destes espaços funerários, mas tão só a utilização dos existentes" (OliveIRA 1995: 678; BuENO RAMíREZ et al. 2010) (Fig. 9). De referir que esta datação é estatisticamente semelhante à obtida na anta das Castelhanas, Marvão - 3220 65 BP (OxA-5432)/ 16571309 cal BC $2 \sigma$; Teste T: 1,$098712 ; \mathrm{Xi}^{2}(.05)$ : 3,84 ; Graus de liberdade: 1 -, igualmente conetável com a fase mais recente de inumação nos monumentos megalíticos da região (OLIVEIRA 1997, 1997a).

Uma quarta datação, obtida a partir de sedimento orgânico extraído do interior do vaso 10 (amostra S3) (vide infra), revelou-se anómala (2270 \pm 40 BP/ 402-207 cal BC $2 \sigma)$. De acordo com Monge Soares (informação pessoal), a degradação da matéria orgânica aderente às paredes do vaso devido a reações com o material do sedimento onde este estava enterrado, bem como devido à ação de micro-organismos, terá originado ácidos fúlvicos e húmicos de idades diferentes do material orgânico que lhe deu origem em consequência da incorporação de carbono de idade diferente (MARTIN \& JOHNSON 1995; WANG et al. 1996). Também outros ácidos do mesmo tipo, existentes no sedimento e com origem na matéria orgânica sedimentar, poderão facilmente ter contaminado a amostra datada.

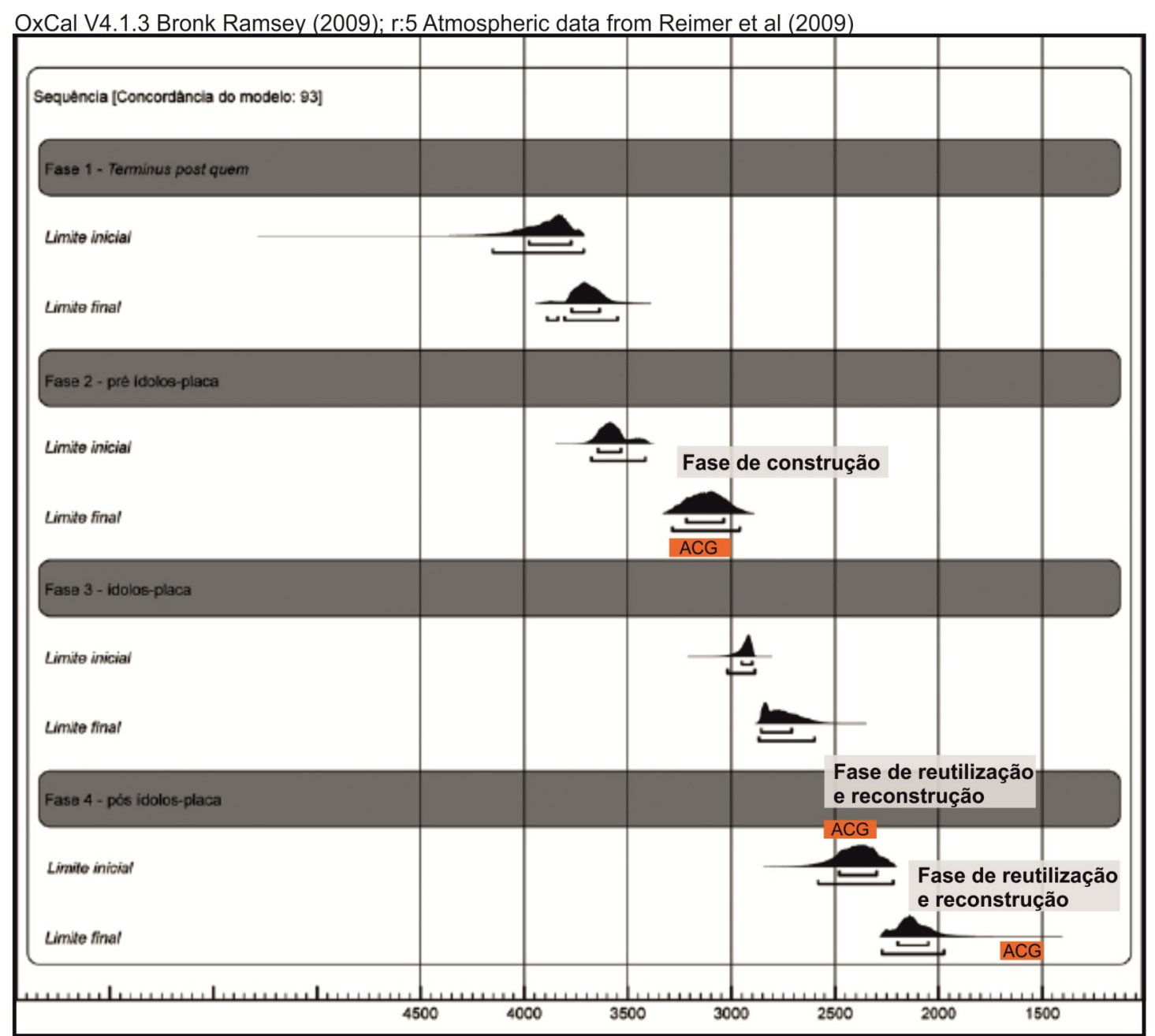

Fig. 9. Datações da anta dos Currais do Galhordas no contexto das "Fases sequenciadas dos sepulcros do Sul de Portugal" (BoAVENTURA \& MATALOTO 2013: 95, modificado). ACG - Anta dos Currais do Galhordas.

Fig. 9. Currais do Galhordas radiocarbon dating in the context of the "Sequenced phases of the megalithic tombs of Southern Portugal" (BOAVENTURA \& MATALOTO 2013: 95, modified). 


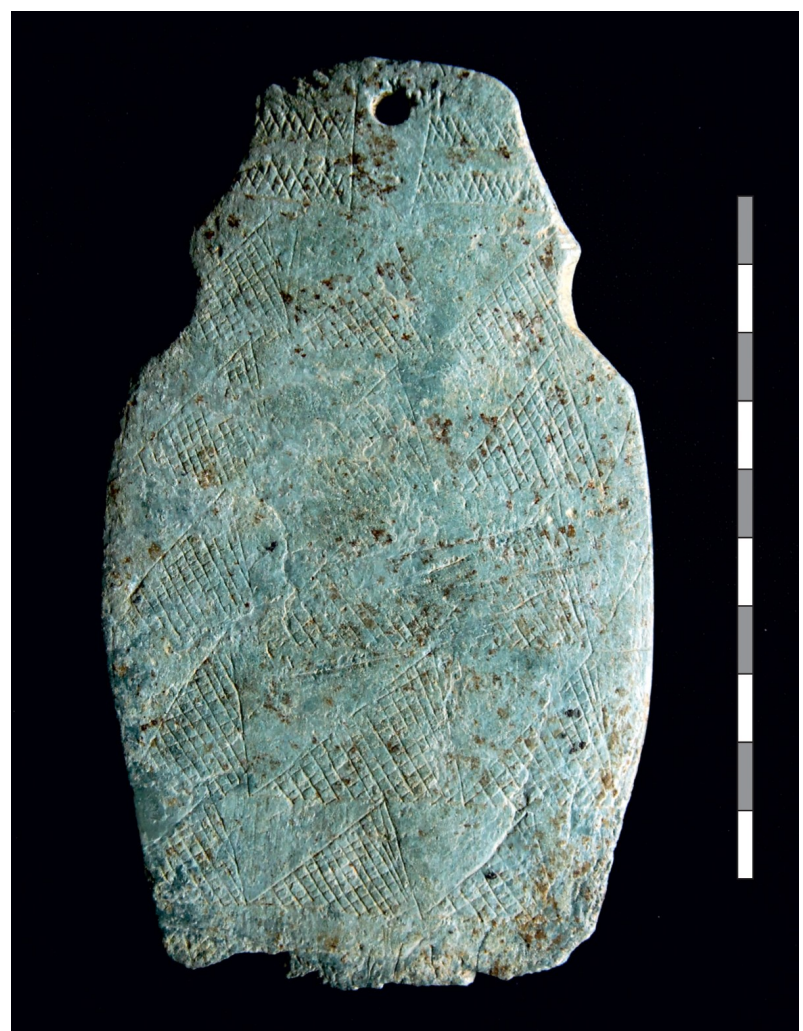

Fig. 10. Uma das placas de "xisto" identificadas na câmara funerária da anta dos Currais do Galhordas com evidências de reafeiçoamento. Fig. 10. One of the slate plaques found in the burial chamber of Currais do Galhordas megalithic tomb, apparently reshaped.

\subsection{Os vasos analisados}

Os conteúdos orgânicos analisados foram extraídos de três vasos que se passa a descrever sumariamente (Fig. 11).

\section{Vaso 6}

Vaso hemisférico de boca ligeiramente reentrante e lábio plano-convexo. Apresenta pasta homogénea e compacta com elementos não plásticos constituídos por quartzo e alguma mica, com dimensões que podem atingir os 3-4 mm. A superfície interior e exterior mostram vestígios de alisamento. Apesar de sujeito a cozedura oxidante existem manchas negras decorrentes de atmosfera redutora. A técnica de fabrico não é clara, sendo provável a modelagem a partir de uma bola de barro.

\section{Vaso 10}

Pequeno vaso com carena baixa bastante pronunciada, corpo troncocónico de paredes tendencialmente côncavas, lábio plano-convexo e base convexa ligeiramente espessada. Tem pasta homogénea e compacta, com grande quantidade de elementos não plásticos muito finos $(<1 \mathrm{~mm})$, constituídos basicamente por quartzo e mica, que lhe conferem uma textura algo arenosa. As superfícies foram bem alisadas, eventualmente polidas; a exterior tem cor bege, a interior e o núcleo cor cinzenta a negra. Trata-se de um recipiente que se distingue pela sua regularidade, simetria e bom acabamento.

\section{Vaso 11}

Pequeno vaso troncocónico de paredes convexas, base plano-convexa e lábio irregular tendencialmente arredondado. A espessura das paredes é muito variável e as respetivas superfícies, interior e exterior, evidenciam alisamento sumário. A pasta é homogénea e compacta incluindo elementos não plásticos muito finos, essencialmente quartzo e mica, que atingem no máximo $1 \mathrm{~mm}$. A tonalidade avermelhada que cobre a totalidade do vaso indica cozedura oxidante ou, mais provavelmente, coloração por engobe. Tal como no vaso 6 , a técnica de fabrico parece ter sido a modelagem a partir de uma pequena bola de barro. Apresenta vestígios de fuligem. 


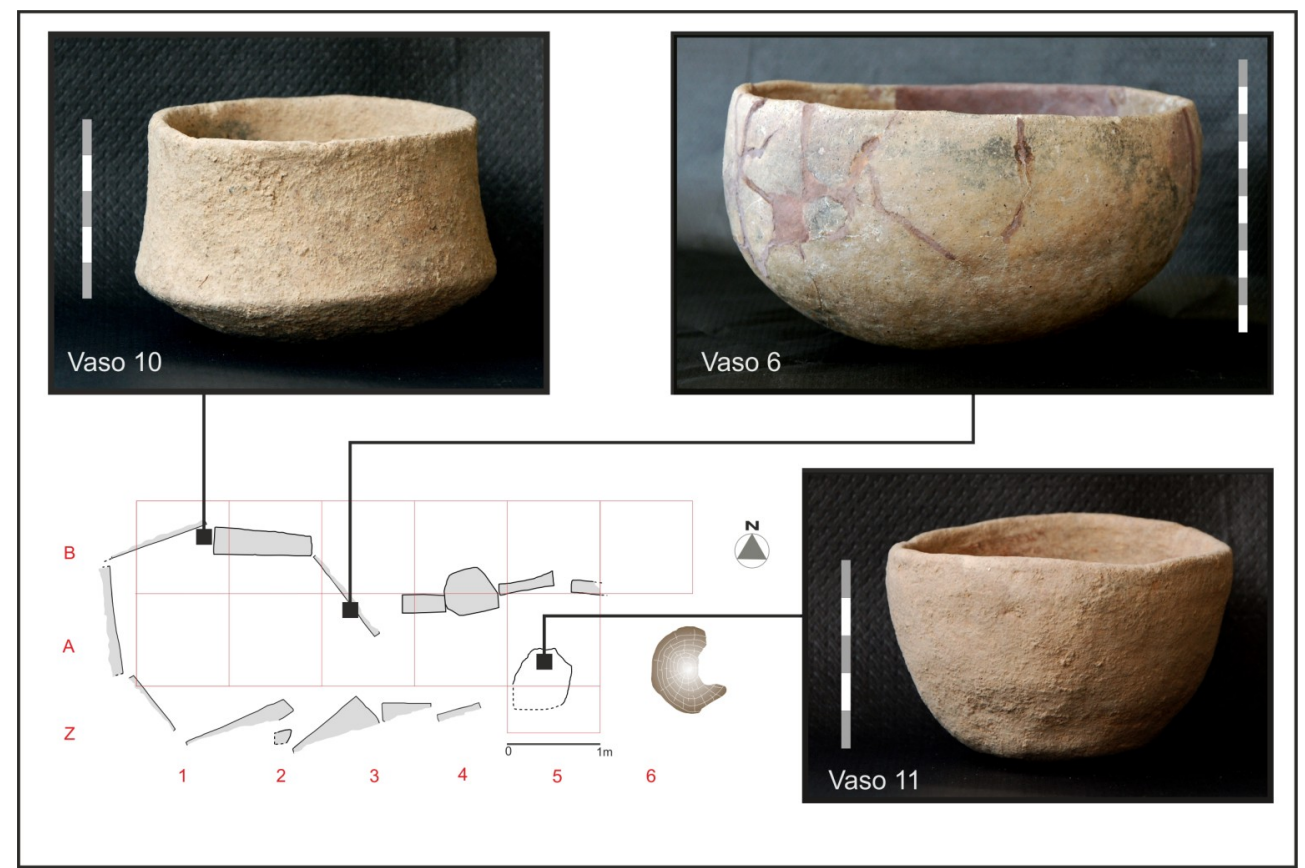

Fig. 11. Distribuição espacial dos vasos analisados na anta dos Currais do Galhordas - vasos 6 e 10: câmara funerária; vaso 11: corredor.

Fig. 11. Spatial location of the analysed vases in Currais do Galhordas - vases 6 and 10: burial chamber; vase 11: passage.

Apesar da grande longevidade da forma expressa no vaso 6 (conhecida desde o Neolítico à Idade do Bronze), avança-se a hipótese de ele se relacionar com uma fase antiga de utilização (ou mesmo com a fase fundacional?) da anta dos Currais do Galhordas. Efetivamente, as características globais deste recipiente permitem a sua inclusão na chamada "cerâmica dolménica", bem documentada, por exemplo, na Gruta do Escoural (Montemor-o-Novo), onde foi datada da segunda metade/último quartel do $4^{\circ}$ milénio $\mathrm{BC}$ (ARAÚJO \& LEJEUNE 1995; BOAVENTURA 2009).

Todavia é provável que os conteúdos orgânicos analisados não remontem a essa fase, mas sim a uma etapa mais tardia. De facto, este recipiente apresentava uma fratura que lhe suprimia parte do bordo e da pança, encontrando-se intencionalmente encostado a um dos esteios da câmara funerária, aparentemente para que este impedisse a saída do seu conteúdo (Fig. 12). Deste modo, o aproveitamento deste recipiente partido sugere tratar-se de uma reutilização, pelo que o material orgânico identificado no seu interior deverá relacionar-se com uma utilização "recente" do monumento. Por outro lado, é de referir que o vaso 6 surgiu num "nível" que se implantava $14 \mathrm{~cm}$ acima daquele de onde foi recolhida a amostra datada do terceiro quartel do $3^{\circ}$ milénio cal BC (vaso $6-\mathrm{Z}: 126 \mathrm{~cm}$; amostra S1 - Z: $140 \mathrm{~cm}$ ). Apesar do critério estratigráfico valer pouco nestes contextos em que se verificam utilizações recorrentes dos espaços, assume-se, para já, que a localização do vaso 6 reflete a posterioridade do seu uso relativamente à referida datação.
De acordo com diversos autores (OlIVEIRA 1995, 1997, 1997a, 1998, 1999-2000; MATALOTO 2007, 2018-no prelo; PONTE et al. 2012; BAPTISTA et al. 2013; MATALOTO et al. 2013; CARDOSO \& GRADIM 2008), as formas carenadas como a documentada pelo vaso 10 remetem para a Idade do Bronze do Sul de Portugal ( $2^{\circ}$ milénio $\left.\mathrm{BC}\right)$, período em que, como se referiu, muitos monumentos megalíticos terão sido revisitados. Tendo em conta que o vaso 10 surgiu à mesma cota do vaso 6 e, portanto, a cerca de $11 \mathrm{~cm}$ acima da amostra $S 1$ (vaso $10-Z$ : $129 \mathrm{~cm}$; vaso $6-\mathrm{Z}$ : $126 \mathrm{~cm}$; amostra S1 - Z: 140 $\mathrm{cm}$ ), pode aceitar-se que também na anta dos Currais do Galhordas esta forma testemunha uma reutilização daquele período cronológico, ou seja, poderá eventualmente relacionar-se com o intervalo 16831499 cal BC $2 \sigma$ obtido a partir da amostra S2, exumada no corredor. Todavia esta proposta não deixa de ser provisória dado que há evidências da ocorrência de formas com carena baixa em contextos mais antigos, nomeadamente do Neolítico Final e do Calcolítico (OliveIra 1997, 2010; DINIZ 2000; GONÇALVES \& SOUSA 2000; MATALOTO \& BoAVENTURA 2009; ANDRADE 2014; GONÇALVES \& ANDRADE 2014; ANDRADE 2016).

Segundo GONÇALVES et al. (1981), a forma em questão corresponde ao vaso carenado de tipo Crato-Nisa. "Morfologicamente, poderão ser confundidos com exemplares mais tardios, nomeadamente, as características taças de tipo Atalaia de iní -cios da Idade do Bronze. Trata-se, no entanto, de um elemento específico dos mobiliários votivos do Megalitismo alto-alentejano (sendo mais escassas 


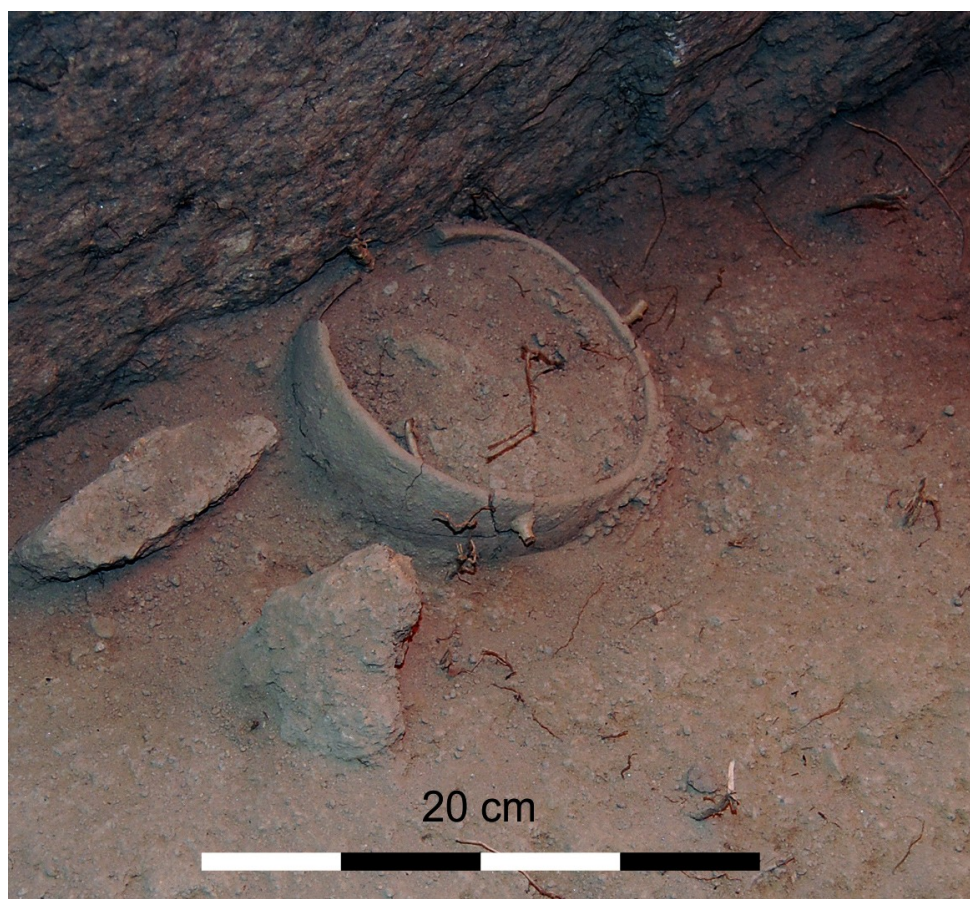

Fig. 12. Posição do vaso 6. Observe-se a zona da fractura encostada ao esteio da câmara funerária.

Fig. 12. Vase 6 position. The fractured side was intentionally placed against one of the chamber orthostats.

ou mesmo inexistentes em áreas do Alentejo central e Baixo Alentejo) nos últimos séculos do IV milénio e primeiros do III milénio BC, surgindo associados a placas de xisto gravadas e pontas de seta de retoque bifacial cobridor" (ANDRADE 2014: 39). Na anta dos Coureleiros 4 (Coureleiros $2 \mathrm{seg}$. Leisner e Leisner, 1959), por exemplo, os pequenos vasos de carena baixa surgem no corredor intratumular, aparentemente associados à datação acima referida - 4240 \pm 150 BP (ICEN-976) / 33382471 cal BC $2 \sigma$. No monumento da Bola de Cera ocorrem na câmara funerária, relacionando-se supostamente com a datação $4360 \pm 50$ BP (ICEN66) / 3104-2887 cal BC $2 \sigma$, para ali obtida (OLIVEIRA 1997).

$\mathrm{Na}$ anta da Horta (Coudelaria de Alter) encontraram-se vasos de carena baixa associados a um "fragmento de uma cabeça de alfinete em osso, canelada, (...) [e a] ídolos-placa em arenito, com decoração em relevo" (OLIVEIRA 2010: 360), conjunto este datado, segundo o autor, de um momento algo posterior a $2800-2760$ cal BC $2 \sigma^{1}$. Importaria confirmar, neste caso, se se trata de material efetivamente coevo ou de uma associação casual decorrente da reutilização e/ou da perturbação a que o monumento foi sujeito

De referir, por outro lado, que os "acabamentos de grande qualidade" presentes nas peças cerâmicas atribuídas à Idade do Bronze do
Sudoeste (MATALOTO et al. 2013: 322) não estão longe do que se observa no vaso 10 .

Como atrás se disse, a tentativa de datação do conteúdo orgânico deste vaso foi mal sucedida, pelo que, infelizmente, não foi possível contribuir para a clarificação da sua real cronologia.

Relativamente ao vaso 11 , está-se uma vez mais perante uma morfologia que transcorre boa parte da pré-história recente, não sendo por isso fácil atribuir-lhe um balizamento cronológico seguro. Tendo em conta o ligeiro aplanamento da base, o possível engobe, a sua articulação com deposições efetuadas no corredor do monumento, normalmente consideradas mais tardias (OLIVEIRA 1995, 1997; BOAVENTURA 2009; BUENO RAMÍREZ et al. 2010; MAtAloto et al. 2013), e ainda o facto de nesse mesmo espaço ter sido obtida a datação ${ }^{14} \mathrm{C}$ do segundo quartel do $2^{\circ}$ milénio cal BC (16831499 cal BC $2 \sigma$ ), assume-se que ele poderá também remeter para a Idade do Bronze do Sul do País. Por outro lado, a semelhança entre os conteúdos orgânicos dos vasos 6 e 11 (vide infra) poderá indiciar que as respetivas (re)utilizações se encontram próximas no tempo, conectando-se, como se disse, com a etapa mais avançada da frequentação da anta.

Em suma, os dados disponíveis - essencialmente a localização espacial e a posição estratigráfica dos recipientes cerâmicos analisados, as data-

${ }^{1}$ A datação convencional BP não é indicada pelo autor, apenas a sua referência: Beta-194312. 
ções absolutas obtidas e a tipologia do vaso $10-$ sugerem que os conteúdos orgânicos identificados poderão remontar à Idade do Bronze Pleno, eventualmente à primeira metade do $2^{\circ}$ milénio $\mathrm{BC}$, relacionando-se deste modo com os "últimos rituais" praticados nos espaços sepulcrais megalíticos. Trata-se, todavia, de uma hipótese cronológica que necessita de verificação futura.

3. OS CONTEÚDOS ORGÂNICOS DOS RECIPIENTES CERÂMICOS: METODOLOGIA DE ANÁLISE

\subsection{Amostragem e preparação das amostras}

Os trabalhos laboratoriais foram realizados segundo as melhores práticas instituídas de modo a minimizar a contaminação das amostras com resíduos orgânicos atuais. Assim, todas elas foram manipuladas com luvas de nitrilo sem pó, obtidas e tratadas com recurso a lâminas de bisturi novas. Evitou-se ainda a utilização de embalagens de plástico, armazenando-se as amostras em papel de alumínio para menorizar o seu contacto com materiais plastificantes. Todo o material de vidro utilizado foi previamente limpo de resíduos orgânicos por imersão em solução cromossulfúrica durante $24 \mathrm{~h}$. A raspagem dos recipientes cerâmicos para obtenção das amostras foi efetuada antes da sua lavagem, consolidação e restauro.

No sentido de detetar eventuais contaminações pós-deposicionais dos recipientes por influência de lençóis de água, águas de escorrência, incorporação de materiais orgânicos provenientes do solo, ou outros, analisou-se uma amostra de controlo constituída por sedimentos areno-siltosos recolhidos na câmara funerária, nas proximidades de dois dos vasos estudados (vasos 6 e 10). Tal análise foi realizada segundo os mesmos procedimentos postos em prática na análise dos materiais extraídos dos recipientes cerâmicos.

A análise aos vasos 6, 10 e 11 da anta dos Currais do Galhordas foi efetuada sobre alíquotas de massa 0,2 a 0,3 g obtidas, como se disse, por raspagem dos fundos e da parte interna das paredes dos recipientes, tendo os materiais sido pulverizados num almofariz de ágata. Efetuaram-se extrações sequenciais com diclorometano e metanol (a discussão dos resultados foi baseada apenas nos extratos de metanol por serem os mais informativos para estas amostras) utilizando um sistema Soxhlet, sendo os extratos orgânicos concentrados em evaporador rotativo, transferidos para vials e secos em corrente reduzida de azoto. Os extratos polares contendo grupos hidroxilo e carboxilo foram sililados por adição de bis(trimetilsilil)trifluroacetamida (BSTFA): Trimetilclorosilano (TMCS) 99:1, seguindo-se 15 minutos num forno a $70^{\circ} \mathrm{C}$.

\subsection{Equipamento e condições cromatográficas}

Utilizou-se um cromatógrafo Varian 4000 Performance operado no modo Full Scan (gama de massas 50 a $600 \mathrm{~m} / \mathrm{z}$ ) nas seguintes condições: a) coluna DB-5MS, $30 \mathrm{~m} \times 0,25 \mathrm{~mm} \times 0,25 \mu \mathrm{m}$ com hélio como gás de arraste a um caudal constante de

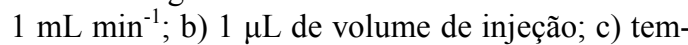
peratura do injetor $250{ }^{\circ} \mathrm{C}$; d) programa de temperaturas: $60{ }^{\circ} \mathrm{C}(1 \mathrm{~min}), 60$ to $150{ }^{\circ} \mathrm{C}\left(10^{\circ} \mathrm{C} \mathrm{min}{ }^{-1}\right)$, 150 to $290{ }^{\circ} \mathrm{C}\left(5^{\circ} \mathrm{C} \mathrm{min}^{-1}\right), 290{ }^{\circ} \mathrm{C}(27 \mathrm{~min})$; e $)$ modo de aquisição, impacto electrónico a $70 \mathrm{eV}$; f) interface e fonte iónica a $290{ }^{\circ} \mathrm{C}$.

A identificação dos compostos baseou-se na análise dos padrões de fragmentação assim como na comparação dos espetros resultantes com espetros das livrarias comerciais Wiley 6 e Nist08.

\subsection{Resultados e discussão}

A análise aos sedimentos areno-siltosos recolhidos do interior da câmara funerária, em associação aos vasos 6 e 10, revelou a ausência de vestígios orgânicos, demonstrando que o material orgânico identificado nos vasos não decorre de qualquer contaminação posterior à sua utilização.

$\mathrm{Na}$ figura 13 apresenta-se, como exemplo, o cromatograma do extrato metanólico respeitante ao vaso 6 (optou-se por não incluir o cromatograma relativo ao vaso 11 por serem similares os cromatogramas e as conclusões obtidas) e nas figuras 14 e 15 os cromatogramas referentes ao vaso 10 .

Da análise efetuada aos três vasos podem retirar-se as seguintes conclusões:

\section{Vaso 6}

A deteção dos ácidos sucínico, málico, cinâmico, fumárico e tartárico é compatível com a presença de vestígios de sumo de uva/frutos vermelhos ou de bagos de uva/frutos vermelhos fermentados (BARNARD et al. 2011; JERKOVIĆ et al. 2011; MCGOVERN 1998; MCGOVERN et al. 1996; MCGOVERN \& MiCHEL 1996; PECCI et al. 2013; TEODOR et al. 2014).

A presença de colesterol, ácido fitânico e alguns ácidos carboxílicos insaturados como os ácidos erúcico (C22:1,cis9, $\omega 9)$, 9-tetradecenoico (C14:1,cis9, 07$)$ (miristoleico) e trans-9hexadecenoico (C16:1,trans9, 07$)$ (palmitoleico) sugerem a existência de vestígios de peixe (HANSEl et al. 2004; HANSEL \& EVERSHED 2009). Esta hipótese é reforçada pela presença dos aminoácidos glicina, aspargina, alanina e tirosina, que podem ter origem na hidrólise das proteínas de peixe (COWEY 1994; DEGENS et al. 1969).

Os compostos oleanitrilo, oleamida e fitol (VACCARO et al. 2013), assim como a hexadecanamida e octadecanamida sugerem a presença de algas ou plantas aquáticas (DEMBITSKY et al. 2000; SUBHASHINI et al. 2013; BAI et al. 2014), corroborando a hipótese anteriormente avançada sobre a presença de peixe.

Os extratos orgânicos encontram-se dominados pelo ácido palmítico, exibindo quantidades mais reduzidas dos ácidos mirístico e esteárico, num padrão típico da degradação de óleos ou gor- 


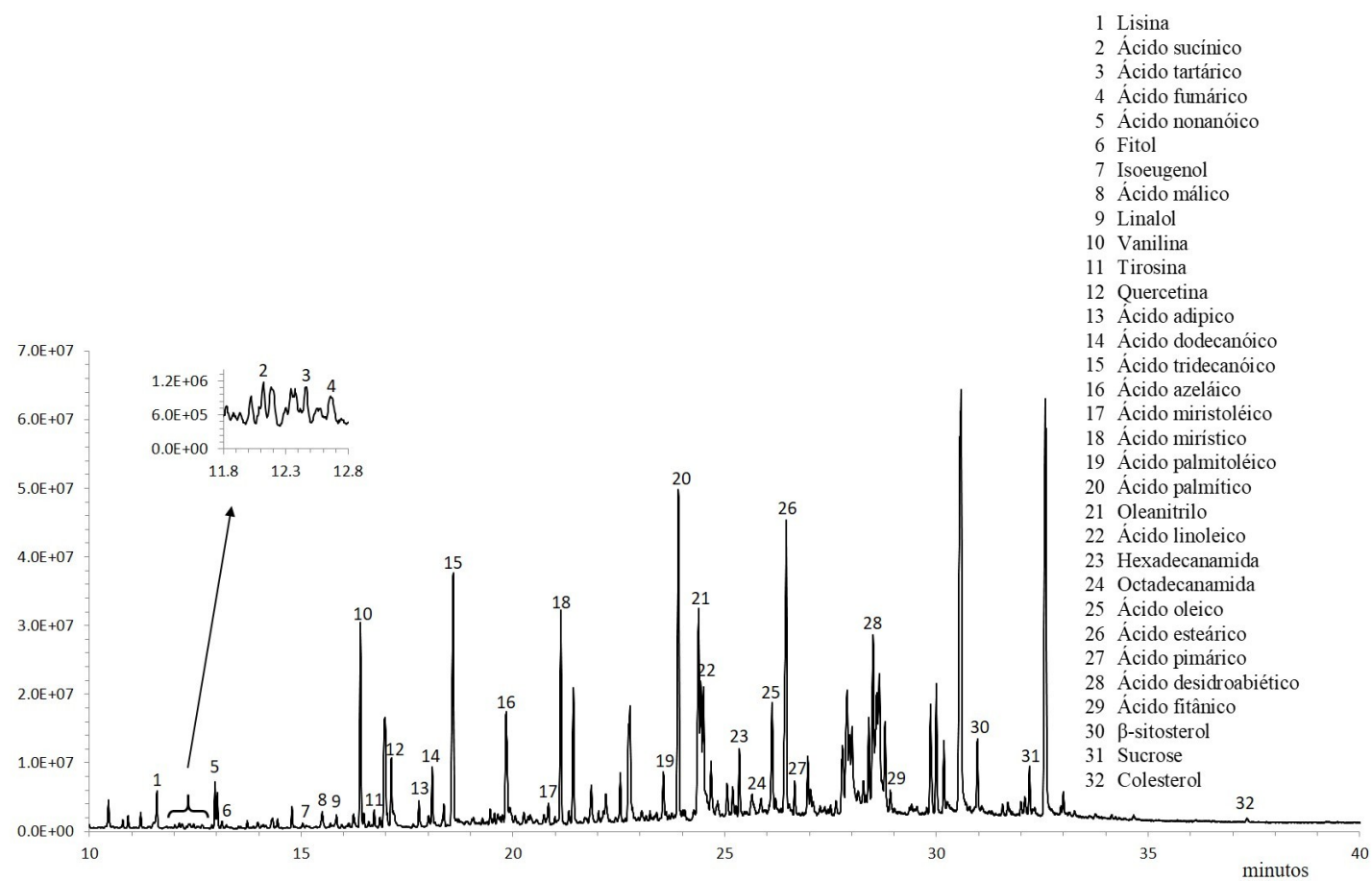

Fig. 13. Cromatograma em modo full scan do extrato de metanol referente ao vaso 6.

Fig. 13. Full scan chromatogram of the methanol extract of vase 6.

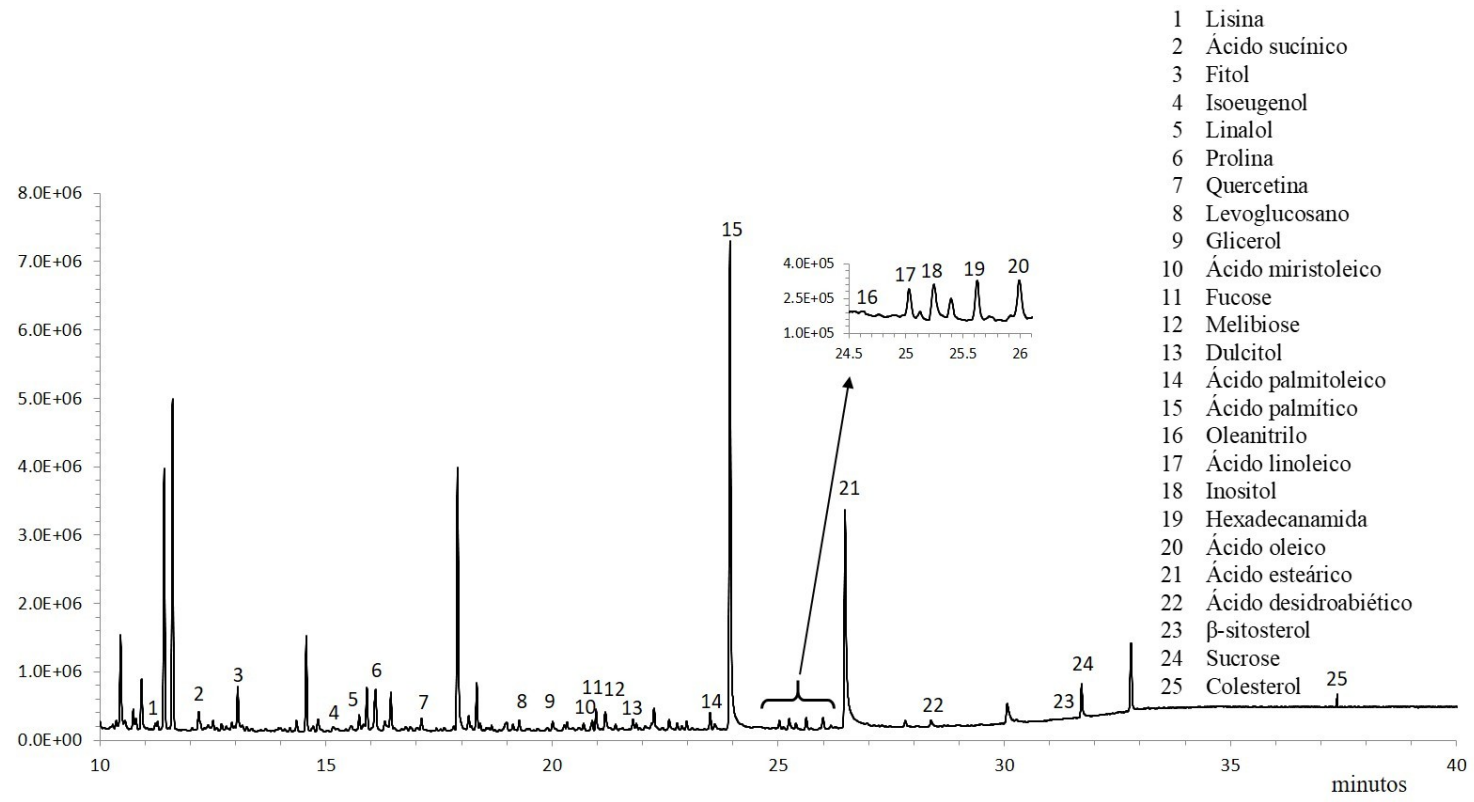

Fig. 14. Cromatograma em modo full scan do extrato de metanol referente ao vaso 10.

Fig. 14. Full scan chromatogram of the methanol extract of vase 10. 


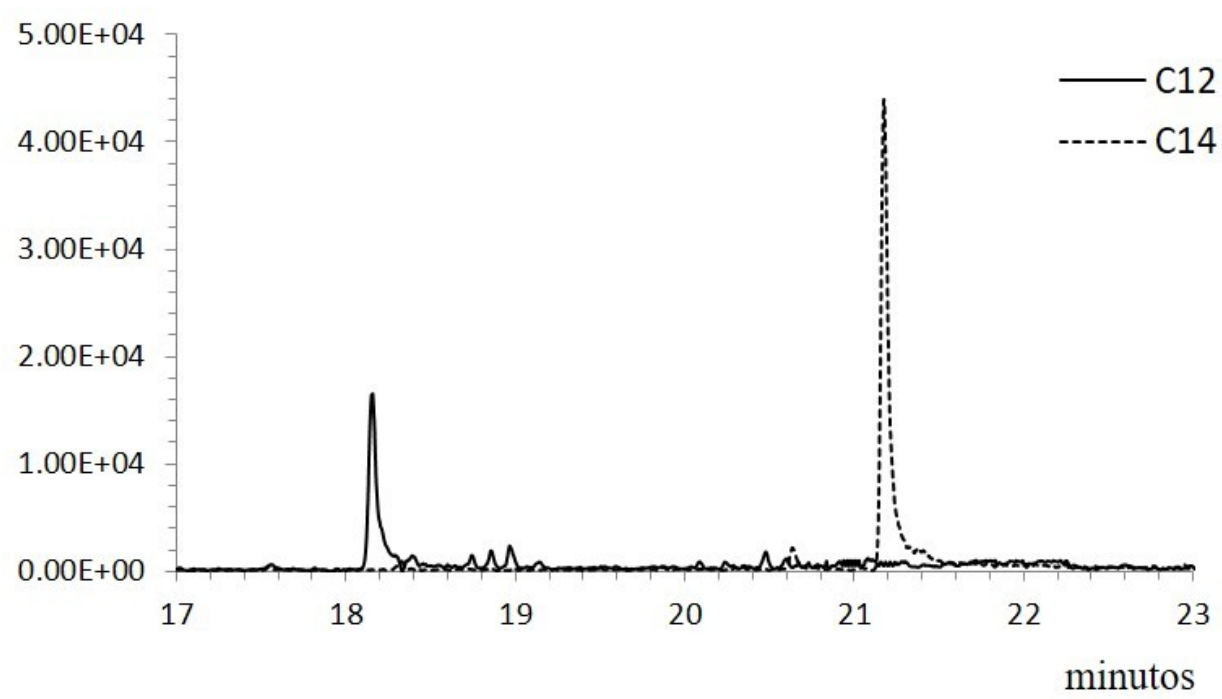

Fig. 15 - Sobreposição de cromatogramas em modo SIM (Selected Ion Monitoring) relativos aos ácidos láurico $(\mathrm{m} / \mathrm{z} 257)$ e mirístico $(\mathrm{m} / \mathrm{z} 285)$.

Fig. 15 - Superimposition of two Selected Ion Monitoring chromatograms of lauric $(\mathrm{m} / \mathrm{z} 257)$ and myristic $(\mathrm{m} / \mathrm{z}$ 285) acids.

duras. De facto, tanto as gorduras animais como os óleos de algumas plantas são ricos em triacilgliceróis que, com o tempo, se degradam a diacilgliceróis, monoacilgliceróis e ácidos carboxílicos, encontrados abundantemente na amostra estudada. Foram ainda identificados diversos compostos caraterísticos de óleos de plantas, como o isoeugenol, linalol e $\beta$-sitosterol (MCGOVERN et al. 2009). A deteção de ácido pimárico e de ácido desidroabiético, um produto da oxidação do ácido abiético (JERKOVIC et al. 2011) suporta a hipótese de se tratar de vestígios de plantas resinosas como o pinheiro (CASEIRO \& OLIVEIRA 2012). A ausência de levoglucosano, um marcador molecular da queima incompleta de biomassa vegetal que se encontra em quantidades apreciáveis nas partículas da pluma de fumo (CASEIRO \& OLIVEIRA 2012; FABBRI et al. 2009; FRASER \& LAKSHMANAN 2000; GAO et al. 2016; KIRCHGEORG et al. 2014; KUO et al. 2008; SIMONEIT 2002; SIMONEIT et al. 1999) indica que o conteúdo do vaso não foi cozinhado.

A interpretação destes resultados sugere que o conteúdo orgânico do recipiente seria composto por bagos de uva ou de frutos vermelhos - destacase o facto das evidencias químicas detetadas neste estudo não permitirem diferenciar vinho da fermentação natural de bagos de uva/frutos vermelhos - e peixe não cozinhado. A este propósito é de referir a existência de um curso de água a poucas centenas de metros da anta (ribeira de Nisa) onde os peixes poderiam ter sido capturados.

Tanto quanto se conhece, encontram-se no Irão as evidências químicas mais antigas do consumo de vinho, remontando ao neolítico (5400 a 5000 BC) os recipientes onde este foi detetado (MCGOVERN 1998; MCGOVERn et al. 1996; MCGOVERN et al. 1997). Os vestígios encontrados na Península Ibérica são, contudo, muito mais recentes. Aqui, a produção vinícola teve início, ao que tudo indica, durante a primeira metade do $1^{\circ}$ milénio $\mathrm{BC}$, devendo-se aos contactos entre a população indígena e as colónias comerciais Fenícias e Gregas (BuXó 2008; NúÑEZ \& WALKER 1989). De facto, ambas as civilizações introduziram gradualmente a videira da espécie Vitis vinifera L., substituindo gradualmente a espécie selvagem Vitis vinifera subsp. sylvestris, variedade abundante durante o Quaternário (IRIARTECHIAPUSSO et al. 2017), particularmente após a última glaciação (LEHMANN \& BÖHM 2011). Esta videira selvagem seria mais frequente no sul da Europa, concentrando-se especialmente nas margens dos rios, em áreas florestadas e em locais húmidos, sobretudo de cota baixa (ARNOLD et al. 1998; LevadouX 1956). Como acima se referiu, a proximidade da anta dos Currais do Galhordas de uma linha de água poderia corroborar a existência de uvas silvestres entre os elementos orgânicos identificados.

\section{Vaso 10}

$\mathrm{Na}$ figura 14 apresenta-se um cromatograma do extrato de metanol obtido a partir do vaso 10 , encontrando-se assinalados os compostos mais relevantes.

Os resíduos orgânicos mostram compostos típicos de gorduras em elevado estado de degradação. De facto, os triacilgliceróis presentes em gorduras animais e em óleos vegetais degradam-se rapidamente em ácidos gordos, exibindo glicerol e elevadas quantidades de ácidos $n$-alcanóicos palmítico $\left(\mathrm{C}_{16: 0}\right)$ e esteárico $\left(\mathrm{C}_{18: 0}\right)$, cujos picos se destacam claramente no cromatograma, e contribuições 
menores dos ácidos de cadeia mais curta. Em condições de elevado grau de degradação é frequente encontrar-se apenas glicerol e ácidos gordos livres, indicando a degradação total dos triacilgliceróis. A razão entre os ácidos $C_{16: 0}$ e $C_{18: 0}$ é por vezes usada como um indicador da origem animal ou vegetal das gorduras encontradas (COPLEY et al. 2005; EVERSHED et al. 2002). Se o ácido palmítico se apresentar mais abundante que o esteárico poderá indiciar a presença de gordura vegetal (COPLEY et al. 2005) enquanto que uma maior quantidade de ácido esteárico aponta para a origem animal da gordura.

Neste contexto vários autores associaram a ocorrência de diferentes razões $\mathrm{C}_{16: 0} / \mathrm{C}_{18: 0}$ à presença de material orgânico de origens distintas (COPLEY et al. 2005; DUDD et al. 1999; ROMANUS et al. 2007).

Assim:

i) $\mathrm{C}_{16: 0} / \mathrm{C}_{18: 0}<1.3 \quad \begin{aligned} & \text { gorduras de animais } \\ & \text { ruminantes }\end{aligned}$
ii) $2.2<\mathrm{C}_{16: 0} / \mathrm{C}_{18: 0}<4.9 \begin{aligned} & \text { leite e derivados, ou } \\ & \text { gorduras de animais não } \\ & \text { ruminantes }\end{aligned}$

iii) $4.0<\mathrm{C}_{16: 0} / \mathrm{C}_{18: 0}<9.4$ - azeite

$\mathrm{Na}$ análise deste vaso detetou-se glicerol, ácidos orgânicos saturados como o sucínico e o láctico, ácidos gordos insaturados como o oleico, linoleico e palmitoleico e elevadas concentrações dos ácidos palmítico e esteárico relativamente aos restantes ácidos, com uma razão $\mathrm{C}_{16: 0} / \mathrm{C}_{18: 0}$ entre 1,4 e 2,5 . De acordo com as informações apresentadas anteriormente esta razão sugere a presença de restos de leite ou de gordura de animais não ruminantes (DUDD et al. 1999; COPLEY et al. 2005; ROMANUS et al. 2007).

A distinção entre gorduras animais ou leite é normalmente efetuada por técnicas isotópicas (BAETEN et al. 2013; COPLEY et al. 2005; EVERSHED et al. 2002; REGERT 2011; ROMANUS et al. 2007) que não se encontraram disponíveis para este trabalho. Contudo, sabendo que a degradação do leite origina quantidades mais elevadas de ácidos de menor cadeia, como os ácidos láurico $\left(\mathrm{C}_{12: 0}\right) \mathrm{e}$ mirístico $\left(\mathrm{C}_{14: 0}\right)$ (CRAMP et al. 2014), pode distinguir-se entre a presença de resíduos de carne ou de leite avaliando-se os níveis destes dois ácidos.

$\mathrm{Na}$ figura 15 apresentam-se os cromatogramas relativos a estes dois compostos, obtidos por extração dos iões com m/z 257 e 285 correspondendo respetivamente aos ácidos láurico e mirístico. Da análise destes cromatogramas podem observar-se picos intensos sugerindo tratar-se de leite, de acordo com os pressupostos anteriormente mencionados. Esta conclusão é também suportada pela presença de aminoácidos provenientes da degradação de proteínas animais, pelo colesterol e pelas formas oxidadas deste composto.

Encontram-se ainda compostos resultantes da queima de biomassa vegetal, particularmente de madeiras resinosas como o pinheiro (levoglucosano e ácido desidroabiético) (SIMONEIT et al. 1999; JERKOVIC et al. 2011), indicando a utilização destas no aquecimento/preparação dos materiais orgânicos ou eventualmente na iluminação da anta.

A presença de compostos caraterísticos de óleos de plantas como o isoeugenol, oleanitrilo, quercetina e fitol pode indicar i) uma contaminação ou reutilização do vaso, ou ii) a utilização de plantas juntamente com o leite, como ainda se faz na preparação de queijo da Serra da Estrela. Refira-se que o leite de animais domésticos, nomeadamente de ovicaprídeos, está normalmente associado a estas primeiras sociedades agro-pastoris.

\section{Vaso 11}

Os resultados da análise química ao vaso 11 encontram-se em linha com os apresentados para o vaso 6 , pelo que se optou por não se apresentar os cromatogramas respetivos.

A interpretação destes resultados sugere que o conteúdo orgânico do recipiente cerâmico seria composto por bagos de uva/frutos vermelhos e peixe. O conteúdo do vaso terá sido cozinhado ou exposto ao fumo.

\section{CONCLUSÕES}

Tendo em conta os dados obtidos, e assumindo o enquadramento temporal acima proposto, pode afirmar-se que na anta dos Currais do Galhordas as "oferendas" funerárias do $2^{\circ}$ milénio BC contemplavam, entre outros elementos, produtos alimentares diversificados, sugerindo práticas de comensalidade associadas aos cerimoniais fúnebres desta época (e.g. PORFírio \& SERRA 2010; BUENO RAMÍREZ et al. 2010).

Alguns destes produtos, tais como os frutos e o peixe, seriam obtidos através de atividades de tipo caça/pesca-recoleção; outros, como o leite e derivados, ligar-se-iam às atividades produtoras, desenvolvidas essencialmente a partir do Neolítico médio (BUENO RAMírez et al. 2010; MONTEIRORODRIGUES 2010, 2011). Deduz-se, portanto, que a prática de ambas as estratégias de obtenção de recursos alimentares - caça-recoleção e criação de animais-agricultura - estaria ainda em curso durante a Idade do Bronze, o que, de certo modo, permite estender no tempo a noção de "economia de amplo espectro" (e.g. FLANNERY 1969). Este aspeto, mais do que traduzir a permanência de um sistema arcaizante, poderá antes justificar o aparecimento de sociedades cada vez mais sedentárias, com maior ligação à terra, maior expressão demográfica e maior complexidade socio-cultural.

Noutros contextos funerários e nalguns habitacionais, genericamente desta fase cronológica e 
geograficamente mais ou menos próximos da anta dos Currais do Galhordas, a presença de vestígios de produtos alimentares em recipientes cerâmicos tem vindo a ser igualmente documentada. $\mathrm{Na}$ Bacia Interior do Tejo, por exemplo, BUENO RAMíREZ et al. $(2008,2010,2010 \mathrm{a}, 2013)$ assinalaram a presença de gorduras animais, sal, restos vegetais (e.g. trigo e cevada), mel (e/ou hidromel), peixe e cerveja, entre outros, em vasos exumados em grutas e em monumentos megalíticos com distintas tipologias.

$\mathrm{Na}$ Sub-meseta Norte, em vasos campaniformes, identificaram-se vestígios de cerveja e de hidromel (DELIBES et al. 2009; GUERRA DOCE 2006); na mesma região, mas em vasos dos "horizontes" Protocogotas e Cogotas I, reconheceu -se um preparado de leite com cereais e gordura de carne (GUERRA DOCE et al. 2011-2012).

Nos sítios de Perdigões e Bela Vista 5, com ocupações dos finais do $4^{\circ}$ e do $3^{\circ}$ milénio $\mathrm{BC}$, a aplicação de cromatografia gasosa com deteção por massa à análise de fragmentos cerâmicos permitiu a deteção de lípidos e, aparentemente, de uma espécie de "sopa" ou guisado com carne, este último nos Perdigões (vaso 5153) (BASTOS 2015).

Num outro contexto - o dos hipogeus e das cistas do Bronze Médio do Baixo Alentejo (Frade et al. 2012) -, o uso de outras técnicas que permitem igualmente a deteção de material orgânico em contextos arqueológicos (neste caso, a espectroscopia de infravermelho, FTIR, e pirólise seguida de cromatografia gasosa acoplada à espectrometria de massa, Py-GC/MS) possibilitou a identificação de gordura de suíno, cera de abelha e própolis em lajes que integram monumentos funerários daquele tipo.

Em suma, a realização mais sistemática de procedimentos químicos que permitam identificar conteúdos orgânicos em vasos pré-históricos (bem como noutros elementos arqueológicos) contribuirá de forma decisiva para um melhor conhecimento das paleodietas (sobretudo quando articulados com a análise dos isótopos estáveis de carbono e de azoto do colagénio de ossos humanos), dos rituais funerários e das estratégias de subsistência das sociedades do passado. No caso do Megalitismo do centrosul de Portugal, e no sentido de melhor contextualizar este tipo de análises, seria fundamental desenvolver projetos que incidissem na datação dos monumentos megalíticos e, sempre que possível, na datação dos recipientes cerâmicos neles exumados.

\section{AGRADECIMENTOS}

Os trabalhos de escavação e de restauro efetuados na anta dos Currais do Galhordas, bem como os estudos complementares realizados - datações pelo radiocarbono e identificação dos conteúdos orgânicos dos vasos cerâmicos por cromatografia gasosa com deteção por massa - foram integralmente financiados pela Câmara Municipal de Castelo de Vide, a quem os autores agradecem.

Agradecem também ao Engenheiro Monge Soares o comentário sobre a datação ${ }^{14} \mathrm{C}$ que se revelou anómala, a João Pedro Tereso (CIBIO) a identificação taxonómica dos carvões datados, assim como aos revisores do texto, que ajudaram a melhorá-lo.

César Oliveira agradece ao Instituto de Ciências e Tecnologias Agrárias e Agro-Alimentares - Porto (ICETA) o seu contrato ao abrigo do projeto NORTE-01-0145-FEDER000011 .

\section{BIBLIOGRAFIA}

ANDRADE, M.A.S. 2009. Megalitismo e comunidades megalíticas na área da Ribeira Grande (Alto Alentejo). Definição e caracterização do fenómeno de «megalitização» da paisagem na área austral do Norte Alentejano. Dissertação de Mestrado, Faculdade de Letras da Universidade de Lisboa, policopiado.

ANDRADE, M.A.S. 2014. Contextos perdidos, obscurantismos helénicos: espólio de um monumento megalítico de Alter do Chão pertencente à colecção de Manuel Heleno. Revista Portuguesa de Arqueologia, 17: 35-60.

ANDRADE, M.A.S. 2016. Sobre os pequenos vasos carenados do megalitismo Alto-alentejano. Questões morfológicas e cronologia. In Inês Pinto Coelho, Joana Bento Torres, Luís Serrão Gil \& Tiago Ramos (Eds), Entre Ciência e Cultura: da Interdisciplinaridade à Transversalidade da Arqueologia. Actas das VIII Jornadas de Jovens em Investigação Arqueológica, CHAM-FCSH/UNL e IEM-FCSH/ UNL: 107-116.

ARAúJo, A.C. \& LeJeune, M. 1995. Gruta do Escoural: Necrópole Neolitica e Arte Rupestre Paleolitica. IPPAR (Trabalhos de Arqueologia 8).

Arnold, C.; Gillet, F. \& Gobat, J. M. 1998. Situations de la vigne sauvage vitis vinifera subsp. silvestris en Europe. Vitis, 37: 159-170.

BAeten, J.; Jervis, B.; De Vos, D. \& Waelkens, M. 2013. Molecular evidence for the mixing of meat, fish and vegetables in Anglo-Saxon coarseware from Hamwic, UK. Archaeometry, 55: 1150-1174.

BaI, X.; Duan, P.; Xu, Y.; Zhang, A. \& Savage, P.E. 2014. Hydrothermal catalytic processing of pretreated algal oil: a catalyst screening study. Fuel, 120: 141-149.

Baptista, L.; Oliveira, L.; SoAres, A.M. \& Gomes, S. 2013. Contributos para a discussão da construção da paisagem nas bacias das Ribeiras do Álamo e do Pisão (Beringel e Trigaches, Beja) entre $\mathrm{IV}^{\mathrm{o}}$ e $\mathrm{I}^{\mathrm{o}}$ Milénios a.C.. In J. Jiménez Ávila, Macarena Bustamante \& M. García Cabezas (Eds.), Actas del VI Encuentro de Arqueología del Suroeste Peninsular (Villafranca de los Barros, 4-6 de Octubre de 2012), Ayuntamiento de Villafranca de Los Barros: 792827.

Barnard, H.; DoOley, A.N.; Areshian, G.; Gasparyan, B. \& FAULL, K. 2011. Chemical evidence for wine production around $4000 \mathrm{BCE}$ in the Late Chalcolithic near Eastern Highlands. Journal of Archaeological Science, 38: 977-984

BAsso, Júlio. 1895. Antas nos concelhos do Crato, Niza e Castello de Vide. O Archeologo Português 1, 7: 191 -192 .

BAstos, B. 2015. Potential of lipid analysis on Prehistoric Portuguese pottery. Apontamentos de Arqueologia e Património, 10, ERA/NIA: 21-31. 
BoAventura, R. 2009. As antas e o Megalitismo da região de Lisboa. Dissertação de Doutoramento apresentada à Universidade de Lisboa. Disponível on-line.

Boaventura, R., Mataloto, R. 2013. Entre mortos e vivos: nótulas acerca da cronologia absoluta do Megalitismo do Sul de Portugal. Revista Portuguesa de Arqueologia, 16: 81-101.

Bueno Ramírez, P.; Barroso, R.; Balbín, R. \& CARreRA, F. 2006. Megalitos y marcadores gráficos en el Tajo Internacional: Santiago de Alcántara (Cáceres). Ayuntamiento de Santiago de Alcántara.

Bueno Ramirez, P.; Barroso-Bermejo, R. \& BalbínBERHMANN, R. 2008. The necropolis of Era de La Laguna, Santiago de Alcántara, Cáceres, in the context of the Megalithism of the Central Region of the International Tagus. In Primitiva Bueno Ramirez, Rosa Barroso-Bermejo \& Rodrigo de BalbínBerhmann (Eds.), Graphical markers and megalith builders in the International Tagus, BAR International Series, 1765: 41-59.

Bueno Ramírez, P.; Barroso-Bermejo, R. \& Balbín BEHRMANN, R. 2010. Megalitos en la cuenca interior del Tajo. Munibe (Suplemento), 32: 152-187.

Bueno Ramírez, P.; BARroso-Bermejo, R. \& BALbínBEHRMANN, R. 2010a. Entre lo visible y lo invisible: registros funerarios de la Prehistoria reciente de la Meseta Sur. In Primitiva Bueno, Antonio Gilman, Concha Martín Morales \& F.-Javier SánchezPalencia (Eds.), Arqueología, Sociedad, Territorio y Paisaje. Estudios sobre Prehistoria Reciente, Protohistoria y Transición al Mundo Romano. Homenaje a M. ${ }^{a}$ Dolores Fernández Posse, Madrid: 53-73.

Bueno Ramírez, P.; Barroso Bermejo, R. \& Balbín BEHRMANN, R. 2012. Mégalithes, Statues, gravures et peintures dans le Bassin intérieur du Tage, Espagne. In M. Sohn \& J. Vaquer (Dir.), Sépultures Collectives et Mobiliers Funéraires de la Fin du Néolithique en Europe Occidentale. Toulouse, Archives d'Écologie Préhistorique: 333-358.

Bueno RAmírez, P.; BARroso-BERmejo, R. \& BALbÍNBEHRMANN, R. 2013. Interior regions and places of collective memory: the megalithism of the interior basin of the Tagus, Iberian Peninsula. A reflection after reading of the Tara project. In Muiris O'Sullivan, Chris Scarre \& Maureen Doyle (Eds.), TARA - From the Past to the Future. Towards a New Research Agenda, Dublin: 484-501.

BuXó, R. 2008. The agricultural consequences of colonial contacts on the Iberian Peninsula in the first millennium BC. Vegetation History and Archaeobotany, 17: $145-154$

CARdoso, J.L. \& Gradim, A. 2008. A necrópole de cistas da Idade do Bronze das Soalheironas, Alcoutim. Primeira notícia dos trabalhos realizados e dos resultados obtidos. Promontoria, 6 (Ano 6): 223248.

CAseiro, A. \& Oliveira, C. 2012. Variations in wood burning organic marker concentrations in the atmospheres of four European cities. Journal of Environmental Monitoring, 14: 2261-2269.

Coelho, P.M. Laranjo. 1924. Terras de Odiana. Subsidios para a sua História Documentada. Medobriga. Ammaia. Aramenha. Marvão. Coimbra, Imprensa da Universidade de Coimbra.
Copley, M.S.; Bland, H.A.; Rose, P.; Horton, M. \& EVERSHED, R.P. 2005. Gas chromatographic, mass spectrometric and stable carbon isotopic investigations of organic residues of plant oils and animal fats employed as illuminants in archaeological lamps from Egypt. Analyst, 130: 860-871.

Costa, F.A. Pereira DA. 1868. Monumentos Prehistóricos Descripção de alguns Dolmins ou Antas de Portugal. Lisboa, Typographia da Academia Real das Ciências.

CowEY, C.B. 1994. Amino acid requirements of fish: a critical appraisal of present values. Aquaculture, 124: $1-11$.

CRAMP, L.J.E.; JONES, J.; SHERIDAN, A.; SMYTH, J.; WHELton, H.; Mulville, J.; Sharples, N. \& EverSHED, R.P. 2014. Immediate replacement of fishing with dairying by the earliest farmers of the northeast Atlantic archipelagos. Proceedings of the Royal Society B, 281: 1-8.

Degens, E.T.; Deuser, W.G. \& HAEdRICH, R.L. 1969. Molecular structure and composition of fish otoliths. Marine Biology, 2: 105-113.

Delibes De Castro, G.; Guerra Doce, E. \& Tresserras -JUAN, J. 2009. Testimonios de consumo de cerveza durante la Edad del Cobre en la tierra de Olmedo (Valladolid). In M.I. del Val Valdivieso \& P. Martínez Sopena (Eds.), Castilla y el mundo feudal: Homenaje al profesor Julio Valdeón, Tomo III, Junta de Castilla y León: 585-599.

DEMBITSKY, V.M.; SHKROB, I. \& ROZENTSVET, O.A. 2000 Fatty acid amides from freshwater green alga Rhizoclonium hieroglyphicum. Phytochemistry, 54: 965-967.

DINIZ, M. 2000. Neolitização e megalitismo: arquitecturas do tempo no espaço. Muitas Antas, Pouca Gente? Actas do I Colóquio Internacional sobre Megalitismo, (Trabalhos de Arqueologia 16): 105-116.

DudD, S.N.; Evershed, R.P. \& GIBSON, A.M. 1999. Evidence for varying patterns of exploitation of animal products in different prehistoric pottery traditions based on lipids preserved in surface and absorbed residues. Journal of Archaeological Science, 26: 1473-1482.

Evershed, R.P.; DudD, S.N.; CoPley, M.S.; BERSTAN, R.; Stott, A.W.; MotTram, H.; BucKley, S.A. \& Crossman, Z. 2002. Chemistry of Archaeological Animal Fats. Accounts of Chemical Research, 35: 660-668.

FABBrI, D.; TORRI, C.; SIMONEIT, B.R.T.; MARYNOWSKI, L.; RUSHDI, A.I. \& FABIAŃSKA, M.J. 2009. Levoglucosan and other cellulose and lignin markers in emissions from burning of Miocene lignites. Atmospheric Environment, 43: 2286-2295.

Fraser, M. P. \& LAKSHMANAN, K. 2000. Using levoglucosan as a molecular marker for the long-range transport of biomass combustion aerosols. Environmental Science \& Technology, 34: 4560-4564.

Frade, J.C.; SoARES, A.M.; CANDEIAS, A.; RIBEIRO, M.I.M Nunes dA Ponte, T.; Serra, M. \& Porfírio, E. 2012. Beeswax and propolis as sealants of funerary chambers during the Middle Bronze Age in the South -Western Iberian Peninsula. In Proceedings of the $39^{\text {th }}$ International Symposium for Archaeometry Centre for Archaeological Science Leuven: 141-145. 
FLANNERY, K. 1969. Origins and ecological effects of early domestication in Iran and the Near East. In Peter J. Ucko \& G.W. Dimbleby (Eds.), The Domestication and Exploitation of Plants and Animals, Chicago: 73-100.

FORENBAHER, S. 1999. Production and Exchange of Bifacial Flaked Stone Artifacts during the Portuguese Chalcolithic, BAR International Series, 756.

Gao, X.; Norwood, M.; Frederick, C.; McKee, A.; MASiello, C. A. \& Louchouarn, P. 2016. Organic geochemical approaches to identifying formation processes for middens and charcoal-rich features. Organic Geochemistry, 94: 1-11.

GONÇALVES, V.S. 1989. Megalitismo e metalurgia no Alto Algarve Oriental: uma aproximação integrada. Lisboa, UNIARQ/INIC.

Gonçalves, V.S.; Treinen-Claustre, F. \& Arruda, A.M. 1981. Anta dos Penedos de S. Miguel (Crato), campanha 1-(81). Clio, 3: 153-164.

GONÇALVES, V.S. \& ANDRADE, M.A. 2014. Pequenos sítios, objectos perdidos, artefactos sem contexto. 2 . Antas inéditas do grupo megalítico Crato-Nisa (Anta das Romeiras e Anta da Ferranha). Revista Portuguesa de Arqueologia, Vol. 17: 61-94.

GonçALVES, V.S. \& SousA, A.C. 2000. O grupo megalítico de Reguengos de Monsaraz e a evolução do megalitismo no Ocidente Peninsular (espaços de vida, espaços de morte: sobre as antigas sociedades camponesas em Reguengos de Monsaraz. In V.S. Gonçalves (Coord.), Muitas antas, pouca gente? Actas do Colóquio Internacional sobre Megalitismo (Trabalhos de Arqueologia 16): 11-104.

GuERra Doce, E. 2006. Sobre la función y el significado de la cerámica campaniforme a la luz de los análisis de contenidos. Trabajos de Prehistoria, 63 (1): 69-84.

Guerra Doce, E.; Delibes De Castro, G.; Rodríguez Marcos, J.A.; Crespo Díez, M.; Gómez PÉrez, A.; Herrán MartíneZ, J.I.; Tresserras JuAN, J. \& Matamala Mellín, J.C. 2011-2012. Residuos de productos lácteos y de grasa de carne en dos recipientes cerámicos de la Edad del Bronce del Valle Medio del Duero. BSAA Arqueología, LXXVII-LXXVIII: 105-137.

Hansel, F.A.; Copley, M.S.; Madureira, L.A.S. \& EverSHED, R.P. 2004. Thermally produced $\omega-(\mathrm{o}-$ alkylphenyl)alkanoic acids provide evidence for the processing of marine products in archaeological pottery vessels. Tetrahedron Letters, 45: 2999-3002.

Hansel, F.A. \& Evershed, R.P. 2009. Formation of dihydroxy acids from Z-monounsaturated alkenoic acids and their use as biomarkers for the processing of marine commodities in archaeological pottery vessels. Tetrahedron Letters, 50: 5562-5564.

IRIARTE-CHIAPUSSO, M.J.; OCETE-PÉREZ, C.A.; HERNÁNDEZ -Beloqui, B. \& OCETE-RuBIO, R. 2017. Vitis vinifera in the Iberian Peninsula: a review. Plant Biosystems - An International Journal Dealing with all Aspects of Plant Biology, 151: 245-257.

Jerković, I.; MariJanović, Z.; Gugić, M. \& RoJe, M. 2011. Chemical profile of the organic residue from ancient amphora found in the Adriatic Sea determined by direct GC and GC-MS analysis. Molecules, 16: 7936-7948.
KIRCHGEORG, T.; SChÜPBACH, S.; KeHRWALD, N.; McWethy, D. B. \& Barbante, C. 2014. Method for the determination of specific molecular markers of biomass burning in lake sediments. Organic Geochemistry, 71: 1-6.

Kuo, L.; Herbert, B.E. \& Louchouarn, P. 2008. Can levoglucosan be used to characterize and quantify char/charcoal black carbon in environmental media? Organic Geochemistry, 39: 1466-1478.

LEHMANN, J. \& BÖHM, J. 2011. Reflections of the presence of Vitis sylvestris during the Ice Age in Iberia. In J. Böhm (Ed.) Atlas das castas da Península Ibérica Lisbon, Dinalivro: 88-90.

LEISNER, G. \& LEISNER, V. 1951. Antas do concelho de Reguengos de Monsaraz. Materiais para o estudo da cultura megalítica em Portugal. Lisboa, Instituto para a Alta Cultura (Reedição de 1985, UNIARCH),

LEISNER, G. \& LeISNER, V. 1956. Die Megalithgräber der Iberischen Halbinsel. Der Westen, Vol. 1, Berlin, Walther de Gruyter.

LEISNER, G. \& LEISNER, V. 1959. Die Megalithgräber der Iberischen Halbinsel. Der Westen, Vol. 2, Berlin, Walther de Gruyter.

LEISNER, G. \& LEISNER, V. 1965. Die Megalithgräber der Iberischen Halbinsel. Der Westen, Vol. 3, Berlin, Walther de Gruyter.

LeISNER, V. 1983. As Diferentes Fases do Neolítico em Portugal, Arqueologia, 7: 7-15.

LEVADOUX, L. 1956. Les populations sauvages et cultivées des Vitis vinifera L. Institut National de la Recherche Agronomique.

MARTIN, C.W. \& Johnson, W.C. 1995. Variation in radiocarbon ages of soil organic matter fractions from Late Quaternary buried soils. Quaternary Research, 43: 232-237.

Mataloto, R. 2007. Paisagem, memória e identidade: tumulações megalíticas no pós-megalitismo altoalentejano. Revista Portuguesa de Arqueologia, Vol. 10, 1: 123-140.

Mataloto, R. 2018-no prelo. Who's U? Um santuário da Idade do Bronze no Cromlech do Arneiro dos Pinhais (Lavre/Ciborro-Montemor-o-Novo). Revista Almansor.

Mataloto, R. \& Boaventura, R. 2009. Entre vivos e mortos nos IV e III milénios a.n.e. do Sul de Portugal: um balanço relativo do povoamento com base em datações pelo radiocarbono. Revista Portuguesa de Arqueologia, Vol. 2, 2: 31-77.

Mataloto, R.; Martins, J.M.M. \& Soares, A.M.M 2013. Cronologia absoluta para o Bronze do Sudoeste. Periodização, base de dados, tratamento estatístico. Estudos Arqueológicos de Oeiras, 20: 303-338.

Mcgovern, P.E.; Mirzoian, A. \& Hall, G.R. 2009. Ancient Egyptian herbal wines. Proceedings of the National Academy of Sciences, 106: 7361-7366.

MCGOVERN, P.E. 1998. Wine for eternity - How molecular archaeologists identified the contents of vessels found in the tomb of an Egyptian king. Archaeology, 51: 28-32. 
McGovern, P.E.; GLusker, D.L.; ExNer, L.J. \& VOIGT, M.M. 1996. Neolithic resinated wine. Nature, 381: $480-481$.

MCGOVERn, P.E.; HARTUng, U.; BADLER, V.R.; GLUSKER, D.L. \& EXNER, L.J. 1997. The beginnings of winemaking and viniculture in the ancient Near East and Egypt. Expedition: The magazine of the University of Pennsylvania, 39: 3-21.

McGovern, P.E. \& Michel, R.H. 1996. The analytical and archaeological challenge of detecting ancient wine: two case studies from the ancient Near East. In P.E. McGovern, S.J. Fleming \& S.H. Katz (Eds.), The origins and ancient history of wine. New York, Gordon and Breach: 57-67.

Monteiro-Rodrigues, S. 2010. Algumas considerações acerca do Processo de Neolitização no Norte de Portugal. In Ana M.S. Bettencourt, M.I. Caetano Alves \& S. Monteiro-Rodrigues (Eds.), Variações Paleoambientais e Evolução Antrópica no Quaternário do Ocidente Peninsular. Braga, APEQ e CITCEM: 73-82.

Monteiro-Rodrigues, S. 2011. Pensar o Neolítico Antigo Contributo para o Estudo do Norte de Portugal entre o VII e o V milénios BC, Viseu (Estudos Préhistóricos, 16).

Monteiro-Rodrigues, S. 2013. A Anta dos Currais do Galhordas (Castelo de Vide - Centro Leste de Portugal): Resultados da primeira campanha de escavação. Estudos do Quaternário, 9: 57-70. Disponível em http://www.apeq.pt/ojs/index.php/apeq

Monteiro-Rodrigues, S. 2016. Resultados da primeira campanha de escavação na Anta dos Currais do Galhordas (Castelo de Vide - Centro Leste de Portugal) - Breve Síntese. Estudos Pré-históricos, 18 (Actas da II Mesa-Redonda "Artes Rupestres da Pré -história e da Proto-história", Porto, Novembro de 2011): 195-202.

NúÑEZ, D.R. \& WALKER, M.J. 1989. A review of palaeobotanical findings of early Vitis in the mediterranean and of the origins of cultivated grape-vines, with special reference to new pointers to prehistoric exploitation in the western mediterranean. Review of Palaeobotany and Palynology, 61: 205-237.

Oliveira, C.; Monteiro-Rodrigues, S. \& AraúJo, A. 2015. Análise química de resíduos orgânicos identificados em vasos da Anta dos Currais do Galhordas (Castelo de Vide, Alto Alentejo, Portugal). In César Oliveira, Rui Morais \& Ángel Morillo Cerdán (Eds.), ArchaeoAnalytics. Chromatography and DNA analysis in Archaeology. Município de Esposende: 85-101.

OliveIRA, J. 1995. Monumentos Megaliticos da Bacia Hidrográfica do Rio Sever. Dissertação de Doutoramento apresentada à Universidade de Évora, policopiado.

OliveIRA, J. 1997. Monumentos Megalíticos da Bacia Hidrográfica do Rio Sever. Marvão (Ibn Maruan).

OLIVEIRA, J. 1997a. Datas absolutas de monumentos megalíticos da bacia hidrográfica do río Sever. Actas del II Congreso de Arqueología Peninsular, Tomo II (Neolítico, Calcolítico y Bronce), Zamora: 29-240.

OliveirA, J. 1998. A Anta da Joaninha e a da Era de Guardias (Cedillo-Cáceres) no ambiente megalítico da foz do rio Sever. Ibn Maruán, 8: 203-245.
OliveIRA, J. 1999-2000. A Anta II de São Gens (Nisa). Ibn Maruán, 9-10: 181-238.

OLIVEIRA, J. 2000. Economia e sociedade dos construtores de megálitos da bacia do Sever. Actas do $3^{\circ}$ Congresso de Arqueologia Peninsular, Vol. III, Porto: ADECAP: 429-444.

Oliveira, J. 2010. Neolítico e Megalitismo na Coudelaria de Alter. In V.S. Gonçalves \& A.C. Sousa (Eds.) Transformação e Mudança no Centro e Sul de Portugal: o $4^{\circ}$ e o $3^{\circ}$ milénios a.n.e. Actas do Colóquio Internacional (Cascais, 2005), Câmara Municipal de Cascais: 357-397.

Oliveira, J.; Pereira, S.; PARreira, J. 2007. Nova Carta Arqueológica do Concelho de Marvão. Edições Colibri e Câmara Municipal de Marvão.

PARoleiro, A.E. BARros. 2016. Estudo dos recipientes cerâmicos dos monumentos megalíticos do conce lho de Castelo de Vide. Dissertação de Mestrado em Arqueologia, Faculdade de Letras da Universidade do Porto, policopiado.

PARreIrA, R. 1996. O conjunto megalítico do Crato (Alto Alentejo): contribuição para o registo das antas portuguesas. Dissertação de Mestrado em PréHistória e Arqueologia apresentada à Faculdade de Letras da Universidade do Porto.

Pecci, A.; Giorgi, G.L.; SAlvini, L. \& CaU Ontiveros, M.A. 2013. Identifying wine markers in ceramics and plasters using gas chromatography-mass spectrometry. Experimental and archaeological materials. Journal of Archaeological Science, 40: 109-115.

Ponte, T.R.N. DA; SoAres, A.M.M.; AraúJo, M. DE F.; Frade, J.C.; Ribeiro, I.; Rodrigues, Z.; Silva R.J.C. \& VAlÉRIO, P. 2012. O Bronze Pleno do Sudoeste da Horta do Folgão (Serpa, Portugal). Os Hipogeus Funerários. O Arqueólogo Português, Série V, 2: 265-295.

PorfírIO, E.M.B. \& SERRA, M.A.P. 2010. Rituais funerários e comensalidade no Bronze do Sudoeste da Península Ibérica: novos dados a partir de uma intervenção arqueológica no sítio da Torre Velha 3 (Serpa). Estudos do Quaternário, 6: 49-66.

Proença, F. TAVAres De. 1910. Antas do districto de Portalegre. Materiaes para o Estudo das Antiguidades Portuguezas. Anno I, $\mathrm{n}^{\circ}$ 1, Leiria, Typographia Leiriense.

REGERT, M. 2011. Analytical strategies for discriminating archeological fatty substances from animal origin. Mass Spectrometry Reviews, 30: 177-220.

REIMER P.J. 2009. Radiocarbon dating: what you always wanted to know but were afraid to ask. http:// www.chrono.qub.ac.uk/instar/papers/ Reimer talk.pdf

ReIMER P.J.; BARD, E.; BAYliss, A.; BeCK, J.W.; BLACKWEll, P.G.; BRONK RAMSEY, C.; BUCK, C.E.; Cheng, H.; EdWARdS, R.L.; FrIEDRICH, M. Grootes, P.M.; GUILDERSON, T.P.; HAFLIDASON, H.; Hajdas, I.; Hatté, C.; Heaton, T.J.; HogG A.G.; Hughen, K.A.; KaISER, K.F.; Kromer, B. MANNING, S.W.; NIU, M.; REIMER, R.W.; RICHARDS, D.A.; SCOTT, E.M.; SOUTHON, J.R.; TURNEY, C.S.M. \& VAN DER PLICHT, J. 2013. IntCal 13 and MARINE 13 radiocarbon age calibration curves 0 50000 years calBP. Radiocarbon, 55(4): 1869 1887. DOI: $10.2458 /$ azu_js_rc. 55.16947 
Rodrigues, M.C.M. 1975. Carta Arqueológica do Concelho de Castelo de Vide. Lisboa, Assembleia Distrital de Portalegre.

Romanus, K.; Poblome, J.; Verbeke, K.; Luypaerts, A. JaCoBs, P.; De Vos, D. \& Waelkens, M. 2007. An evaluation of analytical and interpretative methodologies for the extraction and identification of lipids associated with pottery sherds from the site of Sagalassos, Turkey. Archaeometry, 49: 729-747.

SIMONEIT, B.R.T. 2002. Biomass burning - a review of organic tracers for smoke from incomplete combustion. Applied Geochemistry, 17: 129-162.

Simoneit, B.R.T.; Schauer, J.J.; Nolte, C.G.; Oros, D.R.; Elias, V.O.; Fraser, M.P.; RogGe, W.F. \& CASS, G.R. 1999. Levoglucosan, a tracer for cellulose in biomass burning and atmospheric particles. Atmospheric Environment, 33: 173-182.

Stuiver, M. \& ReImer, P.J. 1993. Calib Radiocarbon Calibration Program, Radiocarbon, 35: 215-230.
Subhashini, P.; Dilipan, E.; Thangaradjou, T. \& PaPen BROCK, J. 2013. Bioactive natural products from marine angiosperms: abundance and functions. Natural Products and Bioprospecting, 3: 129-136.

Teodor, E.; Badea, G.; Alecu, A.; CAlu, L. \& Radu, G. 2014, Interdisciplinary study on pottery experimentally impregnated with wine. Chemical Papers, 68 : 1022-1029.

VACCARO, E.; GHISLENI, M.; ARNOLDUS-HuYZENDVELD, A.; Grey, C.; Bowes, K.; Mackinnon, M.; MerCURI, A.M.; PeCCI, A.; CAU Ontiveros, M.A.; RATTIGHERI, E. \& RINALDI, R. 2013. Excavating the Roman peasant II: excavations at Case Nuove, Cinigiano (GR). Papers of the British School at Rome, 81: 129-179.

Wang, Y., Amundson, R. \& Trumbore, S. 1996. Radiocarbon dating of soil organic matter. Quaternary Research, 45: 282-288. 